\title{
Biosourced Polysaccharide-Based Superabsorbents
}

\author{
Ludovic Llanes ${ }^{1}$, Pascal Dubessay ${ }^{1}$, Guillaume Pierre ${ }^{1}\left[\right.$, Cédric Delattre ${ }^{1,2}{ }^{(\mathbb{C}}$ and \\ Philippe Michaud ${ }^{1, *(D)}$ \\ 1 CNRS, SIGMA Clermont, Institut Pascal, Université Clermont-Auvergne, \\ FS-63000 Clermont-Ferrand, France; ludovic.llanes@etu.uca.fr (L.L.); pascal.dubessay@uca.fr (P.D.); \\ guillaume.pierre@uca.fr (G.P.); cedric.delattre@uca.fr (C.D.) \\ 2 Institut Universitaire de France (IUF), 1 rue Descartes, 75005 Paris, France \\ * Correspondence: philippe.michaud@uca.fr
}

Received: 8 September 2020; Accepted: 10 November 2020; Published: 16 November 2020

\begin{abstract}
In the last decades, many studies have been conducted on new materials to meet a growing industrial demand and to move scientific research forward. Superabsorbents are good examples of materials that have generated special attention in many fields for their ability to absorb and retain water up to 1000 times of their dry weight. They found many applications in hygiene products and other products, for a fast growing market of USD 9.58 Billion in 2019. Most of them are composed of synthetic polymers, which are often not environmentally friendly. Therefore, natural superabsorbents and particularly those based on polysaccharides have received a recent increased interest for their biodegradability, biocompatibility, and renewability. This review focuses on polysaccharide-based superabsorbents, on their properties, synthesis methods, and characterization. Their potential applications in many fields, such as biomedical and hygiene, agriculture, water treatment, and the building sector, are also reported with an interest in products already marketed.
\end{abstract}

Keywords: superabsorbent; polysaccharides; hydrogels; biopolymers; swelling

\section{Introduction}

Superabsorbent polymers (SAPs) are polymers that can absorb water or fluids up to several times their own weight and much more than absorbent polymers. Superabsorbent materials are water-insoluble three-dimensional networks of crosslinked polymers and are called hydrogels, although the terms SAP and hydrogel are often confused [1].

The first hydrogel was entirely synthetic and created in the late 1950s by Wichterle and Lím from poly-2-hydroxyethyl methacrylate. Its first use was the production of contact lenses [2,3]. After the 1980s, hydrogels found other applications, like that of alginic acid microcapsule used for cell engineering by Lim and Sun [4] or the implementation of collagen and shark cartilage to create a hydrogel as wound dressing for burns [5].

Interest in superabsorbent materials has continued to increase since then for their many potential applications in different fields, resulting in a significant increase in the number of publications on this subject in recent years [6]. The majority of traditional hydrogels are made of synthetic polymers like poly(acrylic acid) or polyacrylamide, which are derived from petroleum. They are composed of unsaturated vinyl monomers with hydrophilic groups, such as carboxylic acid for acrylic acid (AA) and amide for acrylamide [7,8]. These groups form hydrogen bonds with water [9], causing its capture and leading to an absorption capacity from 10 to 1000 times the weight of the dry superabsorbent [10]. Due to their high production costs and non-biodegradability, these materials go against the emergence of environmental concern $[7,11]$. So, end users and scientists are now turning to biopolymers, which are synthesized by living organisms or chemically produced from biological materials because they 
present more environmental-friendly properties $[12,13]$. They are for the most part biodegradable, biocompatible, nontoxic, and renewable, but they have poorer water absorption performance and shorter functional life compared to synthetic ones [1,14]. Among them, polysaccharides are the most studied in terms of producing superabsorbents with significant swelling capacity. The most described for the water absorption are cellulose, starch, chitosan, and carrageenan, but many others have been tested for this property [11]. However, they find currently only niche applications in the biomedical field for drug delivery or wound dressing as well as soil conditioner in agriculture $[15,16]$.

With a consumption of more 2.3 million tons of SAPs in 2015 (www.researchinchina.com) and a global market valued at USD 9.58 Billion in 2019 (www.emergenresearch.com) with a growing demand, researchers have been interested in these synthetic and natural materials over the past 25 years through numerous publications. They aim to better understand their structures and properties as well as their potential uses [10]. These data are summarized in Figure 1.

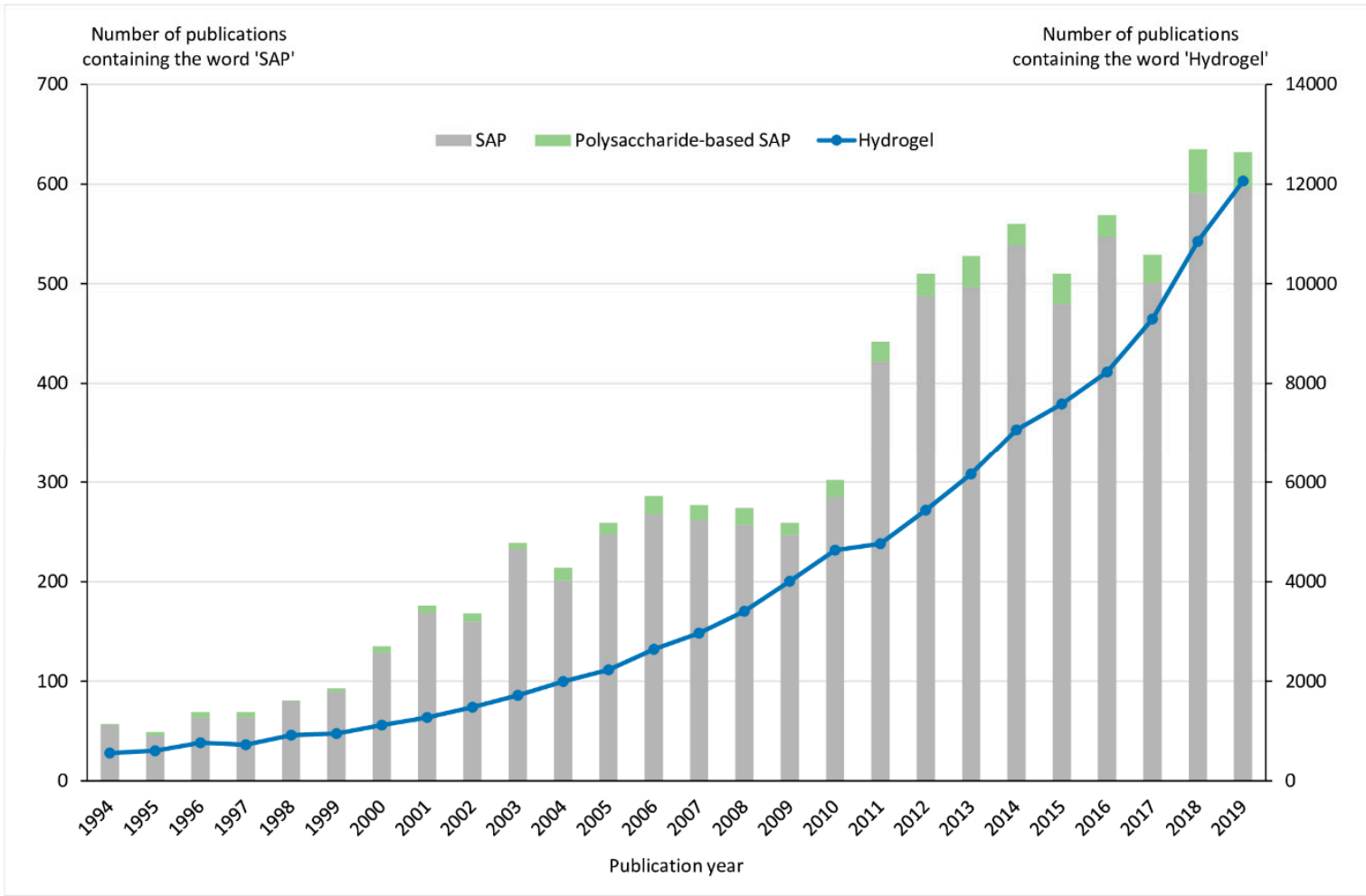

Figure 1. Number of publications containing the words 'SAP', 'Hydrogel,' and 'Polysaccharide-based SAP' by publication year, according to SciFinder Scholar.

It can be observed that the number of publications containing the word "hydrogel" has been steadily increasing since the 2000s. Publications relating to SAPs, on the other hand, have undergone more variations over the years but with a significant increase from 2011 onwards. Between 2010 and 2019, the number of publications on SAPs, including polysaccharide-based SAPs, even doubled, reflecting the growing interest in these materials. SAPs have found many commercial uses in the hygiene field for baby diapers and adult incontinence products. These applications represented around $80 \%$ of the hydrogel production in the world [10] and companies are now expressing their desire to use natural polymers as superabsorbents for their products. These biopolymers, especially polysaccharides, are, therefore, increasingly studied and are the subject of the following parts of this review, which contributes to offer a complete and realistic view of polysaccharide-based superabsorbents from the literature and the current market. 


\section{Definition and Classification}

\subsection{What Is a Superabsorbent and a Hydrogel?}

In the literature, the terms "hydrogel" and "superabsorbent polymer" refer to materials having the capacity to absorb and retain large amounts of fluids [15]. The International Union of Pure and Applied Chemistry (CIUPAC, iupac.org), which is the reference organization for chemical nomenclature and terminology, defined in 2004 a SAP as "a polymer that can absorb and retain extremely large amounts of a liquid relative to its own mass". It can absorb water or an organic liquid up to 1000 times its own weight [17].

On the other hand, a hydrogel is designated as a three-dimensional network of crosslinked hydrophilic polymers. Hydrogels have the property of swelling by water without dissolving, due to the presence of hydrophilic groups (as for example carboxylates, hydroxides, or amides) in the synthetic or natural polymeric backbone [6,9]. They can be considered superabsorbent hydrogels (SAHs) when they absorb water more than 20 times of their initial weight [18]. SAHs are described as the best-known type of hydrogel for business purposes, with a volume representing approximately $80 \%$ of the hydrogel production [11]. Nevertheless, it is important to consider the ionic strength of the absorbed solution because that can affect the swelling degree of these hydrogels, which will no longer present the same superabsorption capacities as with pure water [6].

Both terms appear to be sufficiently different to be used separately. Moreover, SAPs are often composed of ionic monomers and their low crosslinking density allows them to have greater fluid absorption capacity than most hydrogels. However, these words seem to be often confused and, therefore, not used correctly in the literature [15]. Because there is no consensus between the authors, the word superabsorbent will be used to designate all superabsorbent materials, including hydrogels and SAPs.

\subsection{Classification of Superabsorbents}

Superabsorbents can be classified according to different factors, such as morphology, source, crosslinking mechanism, electrical charges, responsiveness to stimuli, polymeric composition, or configuration of polymer chains. These classifications are summarized in Figure 2. Other classifications based on size, durability, functions, and physical state of these materials also exist, but will not be discussed in this review.

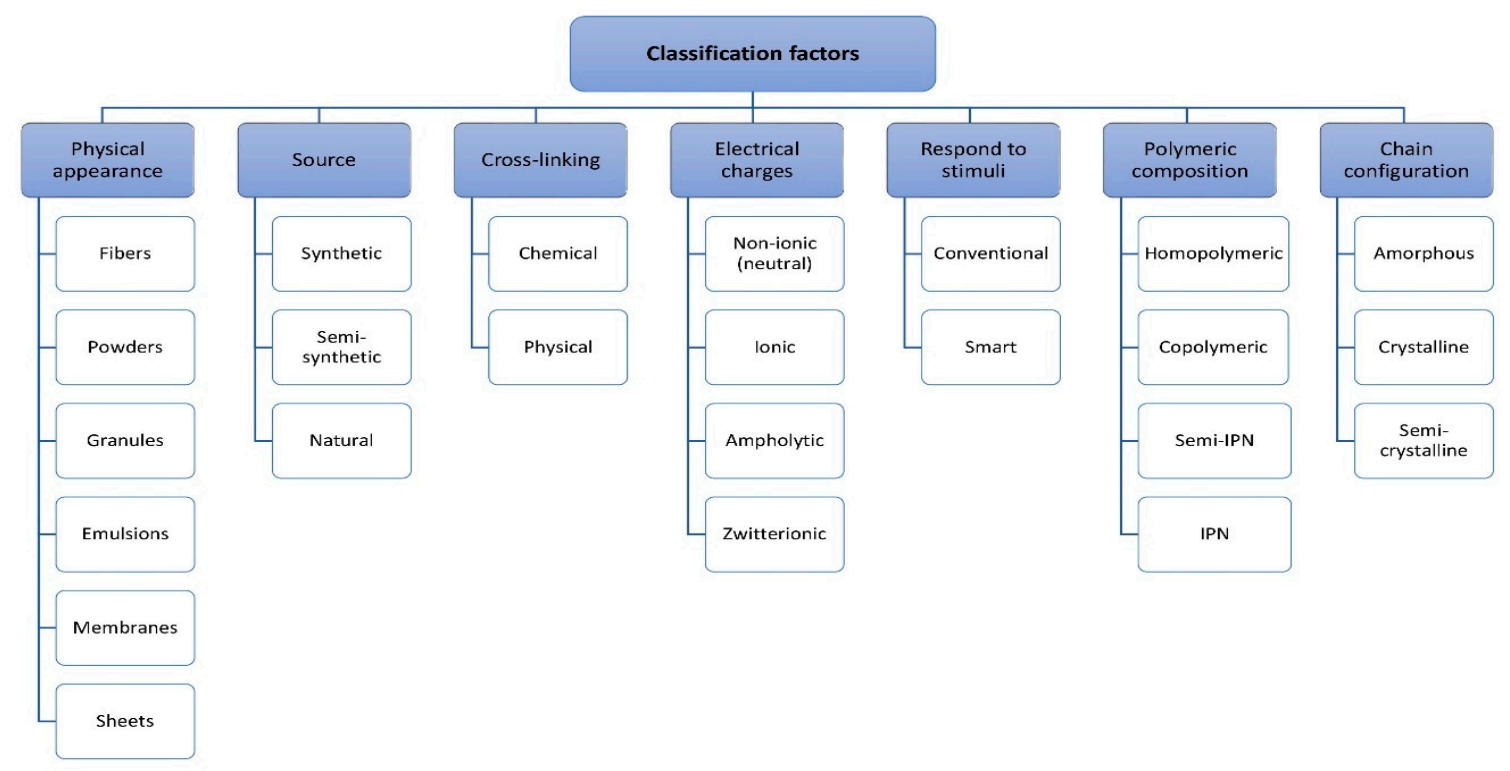

Figure 2. Classification of superabsorbents according to different factors. 


\subsubsection{Classification Based on Physical Appearance}

Superabsorbents can be classified with respect to morphological appearances according to the expected applications. They can exist as fibers, powders, emulsions, granules, membranes, or sheets. Ideally, superabsorbents should have sufficient strength to ensure that their original appearance, and, therefore, structure, is not degraded when absorbing water $[15,19]$. For example, microfibers of a synthetic superabsorbent based on polyacrylate are used as self-healing coating to avoid corrosion on carbon steel [20]. Moreover, superabsorbents based on starch and ethylcellulose with a granular appearance have been used as coating to encapsulate fertilizers [21]. A last example concerns medical application, with the use of a sheet composed of SAPs to absorb the patient's bodily fluids during a surgical operation [10].

\subsubsection{Classification Based on Sources}

Polymers that make up superabsorbents can be of natural, synthetic, or semisynthetic origins. This classification being the most common in the literature, it will be respected in this review [15].

Synthetic superabsorbents are made of polymerized synthetic monomers, which are petrochemical products [7]. The most common synthetic polymers are poly(acrylic acid), polyethylene glycol, and polyacrylamide $[9,14]$. These polymers have the advantage to be easily produced and modified to obtain adapted and specific properties [15,22]. However, despite their advantageous cost and their high mechanical strength, they have poor biodegradability and biocompatibility $[9,15]$.

Superabsorbents can also be synthesized from natural polymers such as polysaccharides or proteins [15] and are then biosourced. These polymers are also called biopolymers since they are extracted from natural resources and they often show good biocompatibility, biodegradability, and nontoxicity. The most commonly used polysaccharides are alginate, chitosan, carrageenan, cellulose, agarose, starch, pectin, and some gums. They do not always have high mechanical strength but they present high swelling for many applications, in the biomedical field for example. The second class of natural polymers is polymers based on proteins, such as collagen or gelatin and they are mainly used in tissue engineering [9].

The third category consists of semisynthetic superabsorbents with natural and synthetic polymers combined. For example, chitosan can be crosslinked with poly(acrylic acid) for a drug delivery application. Generally, this type of superabsorbent is synthesized by graft polymerization of a synthetic polymer to a natural backbone. This blend of polymers allows these materials to be more sustainable than synthetic superabsorbents and to have a stronger mechanical force than natural superabsorbents. However, these copolymers are only partially biobased and biodegradable, which can limit their applications [15].

\subsubsection{Classification Based on Crosslinking}

Superabsorbents can be chemically or physically crosslinked. When the formation mechanism of the polymeric network is chemical, the polymer chains are connected by covalent bonds with strong energy greater than $100 \mathrm{~kJ} \cdot \mathrm{mol}^{-1}$ [23]. The resulting superabsorbents are qualified as irreversible or permanent and have stable properties with good mechanical strength. Free-radical polymerization is the most used chemical mechanism [9]. However, all chemical crosslinkings need a polymer backbone and a crosslinker. Polysaccharides such as cellulose, chitosan, alginate, or starch can form chemical superabsorbents in the presence of chemical reagents used as crosslinkers [18].

The majority of physical superabsorbents are rather reversible or nonpermanent due to noncovalent and weak bonds (with energy up to $40 \mathrm{~kJ} \cdot \mathrm{mol}^{-1}$ ) as electrostatic interaction, hydrogen bonding, and hydrophobic interaction $[9,23]$. No toxic crosslinking agents are present for this type of crosslinking, allowing associated superabsorbents to be widely used for applications in pharmaceutical and biomedical fields [9]. The combination of starch and carboxymethylcellulose, for example, can form physical superabsorbents [18]. 


\subsubsection{Classification Based on Electrical Charges}

In this classification based on the presence of electrical charges located on the backbone or side chains of superabsorbent, four categories can be distinguished. Nonionic or neutral superabsorbents as those made of neutral polysaccharides, such as dextran or agarose.

Ionic superabsorbents include anionic or cationic species. For example, in the field of polysaccharidic-based superabsorbent, carrageenan is an anionic macromolecule (sulfates groups) whereas chitosan is a cationic one when it is dissolved in acidic solutions [9]. Similarly, AA or aminoethyl methacrylate are synthetic monomers with an anionic and cationic characters, respectively. These materials are generally biocompatible.

Ampholytic superabsorbents have concomitant positive and negative charges. Synthetic monomers like maleic anhydride or $\mathrm{N}$-vinyl succinimide make it possible to produce this type of superabsorbents [18].

The last category is zwitterionic superabsorbents, which contain the same charges as ampholytic superabsorbents, but that neutralize themselves to obtain a zero overall net charge [15]. For example, the mix of xanthan (an anionic polysaccharide) with polycationic chitosan led to zwitterionic superabsorbent [9].

\subsubsection{Classification Based on Respond to Stimuli}

When the three-dimensional conformation of a superabsorbent change with environmental stimuli, we can talk about smart or environmentally responsive superabsorbents. Otherwise, superabsorbents are conventional or environmentally unresponsive. In the first case, they can respond to stimuli such as temperature, $\mathrm{pH}$, ionic strength, light, pressure, and electric and magnetic fields. When the stimuli disappear, they systematically return to a steady state. These superabsorbents are often used in drug delivery $[9,15]$. For example, $\mathrm{pH}$-sensitive alginate-based superabsorbents have been investigated as candidates for delivery systems of drugs in the gastrointestinal tract [24].

\subsubsection{Classification According to the Polymeric Composition}

The nature of polymers constituting superabsorbents can lead to another classification. Indeed, superabsorbents can be homopolymeric, heteropolymeric, semi-interpenetrating, or interpenetrating polymer networks.

Homopolymeric superabsorbents are crosslinked networks of polymers composed of a unique species of polymer. Cellulose-based superabsorbents are examples of this type of network [9].

Heteropolymeric superabsorbents are composed of two or more different polymers with one hydrophilic or more, which can be arranged randomly on the polymer network, alternately, or in block configuration [25]. Carboxymethylcellulose and carboxymethylchitosan mixed were reported to form copolymeric material for a metal absorption application.

Interpenetrating polymer network (IPN) is the combination of two different crosslinked polymers that interpenetrate in the presence of a crosslinking agent. An example of this type of material is the crosslinking of alginate and hydrophobically modified ethyl hydroxyl ether cellulose. When only one polymer is crosslinked and the other is not, we can talk about semi-interpenetrating polymer network (semi-IPN). A superabsorbent based on crosslinked synthetic polymers and linear carboxymethylchitosan can be quoted as an example [18]. A superabsorbent nanocomposite composed of a starch backbone and grafted synthetic monomers with polyvinyl alcohol and clinoptilolite has also recently been studied as a semi-IPN [26].

\subsubsection{Classification Based on Chain Configuration}

The latest classification of superabsorbents is based on chain structure or configuration. Amorphous and crystalline superabsorbents (orderly arrangements) were reported as well as semicrystalline materials, which are mixtures of the two previous ones [25]. For example, chitin, which can form superabsorbent, can have a semicrystalline morphology with its acetyl groups 
distributed heterogeneously along the polymer chains when it is obtained by reaction in the solid state [27]. Amylose and amylopectin, the two starch components, are semicrystalline and crystalline, respectively [9].

\subsection{Polysaccharides Used for Superabsorbents}

Polysaccharides have been the most used and studied among natural superabsorbents for their interesting properties and various applications. The most abundant polysaccharides found in nature are cellulose and chitin [11] from terrestrial plant and animal origin, respectively, but polysaccharides are present in all organisms including seaweeds and microorganisms [28].

Polysaccharides are polymers made up of a single (homopolysaccharides) or several (heteropolysaccharides) monosaccharidic species linked together by glycosidic linkages. Among homopolysaccharides, there are starch, cellulose, or carrageenan, and alginate, agarose, or chitosan are heteropolysaccharides [8]. They can also be linear such as hyaluronic acid or branched like dextran or Arabic gum. Finally, some of them are anionic such as alginate and carrageenan, cationic such as chitosan when it is dissolved in acidic solutions, or nonionic such as guar gum [9]. Most polysaccharides are biodegradable, nontoxic, and renewable. Moreover, their charged and hydroxyl groups allow them to have strong affinity to water, giving them a good potential as superabsorbent materials. In the literature, the most described absorbent polysaccharides are alginate, chitin and chitosan, starch, carrageenan, agar and agarose, pectin, hyaluronic acid, dextran, cellulose, and gums (Table 1). The most employed for superabsorbent applications are starch and heteropolysaccharides [11].

Their derivatives are also studied for superabsorbent applications because chemical modifications can improve their physicochemical properties and bring them new advantageous properties [11,29-31]. For example, many polysaccharides can be modified by addition of vinyl groups (as methacrylate ones) to produce superabsorbents. An illustration of this, a modified pectin-based superabsorbent has shown good water superabsorption in the presence of salt solution whereas the unmodified pectin-based superabsorbents have not developed this property [6]. Starch sulfate is another example of modified polysaccharide. The hydrogel associated has improved salt absorbency because sulfate groups ionize more easily than carboxylic ones. Therefore, there is less association with mobile ions in salt solution and the ionic strength has less effect on the swelling of superabsorbent hydrogel [11]. 
Table 1. Characteristics of polysaccharides used for natural superabsorbent materials.

\begin{tabular}{|c|c|c|c|c|c|c|c|}
\hline Polysaccharides & Compositions & Glycosidic Linkages & Origins & Molecular Weights & $\begin{array}{l}\text { Properties and } \\
\text { Characteristics }\end{array}$ & Applications & References \\
\hline Alginate & $\begin{array}{l}\text { L-guluronic acid and } \\
\text { D-mannuronic acid. }\end{array}$ & $\begin{array}{c}\alpha-(1,4) \text { and } \\
\beta-(1,4)\end{array}$ & Brown algae & $50-10^{6} \mathrm{~kg} / \mathrm{mol}$ & $\begin{array}{l}\text { Biocompatible, } \\
\text { immunogenic and } \\
\text { gel-forming property. }\end{array}$ & $\begin{array}{l}\text { In drug release, tissue engineering and } \\
\text { cells encapsulation), food industry } \\
\text { (stabilizers and emulsifiers). }\end{array}$ & $\begin{array}{l}{[27]} \\
{[28]}\end{array}$ \\
\hline Agar & $\begin{array}{l}\text { Agarose and agaropectin with } \\
\text { mainly D- and } \\
\text { L-galactopyranose. }\end{array}$ & $\begin{array}{c}\alpha-(1,3) \text { and } \\
\beta-(1,4)\end{array}$ & Red algae & 1 & Gelling properties. & $\begin{array}{l}\text { In tissue engineering, to encapsulate cells } \\
\text { and as growth medium. }\end{array}$ & $\begin{array}{l}{[15]} \\
{[27]}\end{array}$ \\
\hline Agarose & $\begin{array}{l}\text { D-galactopyranose and } \\
\text { 3,6-anhydro-L-galactopyranose. }\end{array}$ & $\begin{array}{c}\alpha-(1,3) \text { and } \\
\beta-(1,4)\end{array}$ & Red algae & 1 & $\begin{array}{l}\text { Agarose is biocompatible } \\
\text { and has high water } \\
\text { absorption capacity. }\end{array}$ & $\begin{array}{l}\text { For gel electrophoresis, immobilization } \\
\text { of enzymes, cells encapsulation and as } \\
\text { growth medium. }\end{array}$ & $\begin{array}{l}{[15]} \\
{[27]} \\
{[29]}\end{array}$ \\
\hline Pectin & $\begin{array}{l}\text { D-galacturonic acid with } \\
\text { rhamnogalacturonan regions. }\end{array}$ & $\alpha-(1,4)$ & $\begin{array}{l}\text { Cell walls of terrestrial } \\
\text { plants and from citrus } \\
\text { fruits }\end{array}$ & Around $10^{2} \mathrm{~kg} / \mathrm{mol}$ & 1 & $\begin{array}{l}\text { In food industry as colloidal stabilizer } \\
\text { and gelling agent. }\end{array}$ & $\begin{array}{l}{[11]} \\
{[27]} \\
{[30]}\end{array}$ \\
\hline Starch & $\begin{array}{l}\text { Amylose and branched } \\
\text { amylopectin with } \\
\text { D-glucopyranose. }\end{array}$ & $\begin{array}{c}\alpha-(1,4) \text { and } \\
\alpha-(1,6) .\end{array}$ & Green plants & $\begin{array}{l}\text { Amylopectin: } 10^{7}-10^{9} \text { and } \\
\text { amylose: } 10^{5}-10^{6} \mathrm{~g} / \mathrm{mol}\end{array}$ & $\begin{array}{l}\text { Abundant availability in } \\
\text { nature, biocompatible, } \\
\text { good mechanical } \\
\text { resistance and plasticity. }\end{array}$ & $\begin{array}{l}\text { In products for drug delivery and release. } \\
\text { Also used as food thickeners, } \\
\text { cosmetic creams and in adhesive and } \\
\text { paper industries. }\end{array}$ & $\begin{array}{c}{[9]} \\
{[28]}\end{array}$ \\
\hline Hyaluronic acid & $\begin{array}{l}\text { Disaccharide with } \\
\text { D-glucuronic acid and } \\
\text { N-acetyl-D-glucosamine. }\end{array}$ & $\begin{array}{c}\beta-(1,4) \text { and } \\
\beta-(1,3)\end{array}$ & $\begin{array}{l}\text { Vertebrates tissues or } \\
\text { produced by bacteria }\end{array}$ & $50-2.10^{6} \mathrm{~kg} / \mathrm{mol}$ & $\begin{array}{l}\text { Biocompatible and } \\
\text { mucoadhesivity. }\end{array}$ & $\begin{array}{l}\text { In tissue engineering, drug delivery and } \\
\text { wound healing. }\end{array}$ & $\begin{array}{l}{[9]} \\
{[28]}\end{array}$ \\
\hline Carrageenan & $\begin{array}{l}\text { D-galactose and } \\
\text { D-anhydrogalactose } \\
\text { with ester sulfate groups. }\end{array}$ & $\begin{array}{c}\alpha-(1,4) \text { and } \\
\beta-(1,3)\end{array}$ & Red algae & Above $100 \mathrm{~kg} / \mathrm{mol}$ & $\begin{array}{c}\text { Biocompatible, } \\
\text { water-retention and } \\
\text { gel-forming properties. }\end{array}$ & $\begin{array}{l}\text { In drug delivery, tissue engineering and } \\
\text { wound healing. In food industry, } \\
\text { as emulsifier, thickener and stabilizer. }\end{array}$ & $\begin{array}{l}{[15]} \\
{[28]}\end{array}$ \\
\hline Dextran & D-glucopyranose. & $\begin{array}{c}\alpha-(1,6) \text { and } \\
\alpha-(1,3)\end{array}$ & $\begin{array}{l}\text { Produced by lactic } \\
\text { acid bacteria }\end{array}$ & $9.10^{3}-5.10^{5} \mathrm{~kg} / \mathrm{mol}$ & $\begin{array}{l}\text { High cost and } \\
\text { nonavailability. }\end{array}$ & $\begin{array}{l}\text { In biomedical for protein and drug } \\
\text { delivery, tissue engineering and as } \\
\text { bioadhesive. }\end{array}$ & $\begin{array}{c}{[9]} \\
{[28]}\end{array}$ \\
\hline Chitin & $\mathrm{N}$-acetylglucosamine. & $\beta-(1,4)$ & $\begin{array}{c}\text { Exoskeleton of } \\
\text { animals and cell walls } \\
\text { of fungi }\end{array}$ & I & $\begin{array}{l}\text { Biocompatibility, proteins } \\
\text { affinity, antibacterial and } \\
\text { gel-forming properties. }\end{array}$ & $\begin{array}{l}\text { In tissue engineering, drug delivery and } \\
\text { wound healing. }\end{array}$ & $\begin{array}{l}{[27]} \\
{[28]}\end{array}$ \\
\hline Chitosan & $\begin{array}{c}\text { D-glucosamine and } \\
\text { N-acetyl-D-glucosamine. }\end{array}$ & $\beta-(1,4)$ & $\begin{array}{c}\text { Exoskeleton of } \\
\text { animals and cell walls } \\
\text { of fungi }\end{array}$ & I & $\begin{array}{l}\text { Biocompatible, } \\
\text { immunostimulating and } \\
\text { mucoadhesive properties. }\end{array}$ & $\begin{array}{l}\text { In drug delivery, wound dressing, } \\
\text { tissue engineering and cell encapsulation. } \\
\text { In water treatment as absorbent. }\end{array}$ & [28] \\
\hline Cellulose & D-glucose. & $\beta-(1,4)$ & $\begin{array}{l}\text { Cell wall of terrestrial } \\
\text { plants, algae and } \\
\text { bacteria }\end{array}$ & / & $\begin{array}{l}\text { Biocompatibility, thermal } \\
\text { and chemical stability and } \\
\text { high hydrophilicity. }\end{array}$ & $\begin{array}{l}\text { In drug delivery, tissue engineering and } \\
\text { wound dressing. And in paper and } \\
\text { textile industries. }\end{array}$ & $\begin{array}{c}{[9]} \\
{[28]}\end{array}$ \\
\hline Guar gum & $\begin{array}{l}\text { D-mannopyranose and } \\
\text { D-galactopyranose. }\end{array}$ & $\begin{array}{c}\beta-(1,4) \text { and } \\
\alpha-(1,6)\end{array}$ & $\begin{array}{l}\text { Seeds of terrestrial } \\
\text { plants }\end{array}$ & / & Thickens spontaneously. & $\begin{array}{l}\text { In the oil industry as thickener, in food as } \\
\text { food supplement and in drug delivery. } \\
\text { And as binder, emulsifier and stabilizer. }\end{array}$ & $\begin{array}{c}{[9]} \\
{[28]}\end{array}$ \\
\hline Xanthan gum & $\begin{array}{l}\text { D-glucose with } \\
\text { D-mannose and } \\
\text { D-glucuronic acid. }\end{array}$ & $\begin{array}{c}\alpha-(1,3), \\
\beta-(1,4) \text { and } \beta-(1,2)\end{array}$ & $\begin{array}{l}\text { Produced by bacterial } \\
\text { fermentation }\end{array}$ & Around $10^{3} \mathrm{~kg} / \mathrm{mol}$ & $\begin{array}{l}\text { Good stability in aqueous } \\
\text { solution, suspending and } \\
\text { thickening properties. }\end{array}$ & $\begin{array}{l}\text { In food industry as stabilizer and } \\
\text { suspending agent but also in biomedical } \\
\text { for drug release. }\end{array}$ & $\begin{array}{l}{[9]} \\
{[27]} \\
{[28]}\end{array}$ \\
\hline Arabic gum & $\begin{array}{l}\text { D-galactopyranose with } \\
\text { L-arabinofuranose, } \\
\text { L-rhamnopyranose and } \\
\text { D-glucopyranose. }\end{array}$ & $(1,3)$ and $(1,6)$ & $\begin{array}{l}\text { Stems and branches of } \\
\text { terrestrial plants }\end{array}$ & I & $\begin{array}{l}\text { Emulsifying, } \\
\text { film-forming, stabilizing } \\
\text { and thickening properties. }\end{array}$ & $\begin{array}{l}\text { In industries as fiber and food additive } \\
\text { as well as biomaterial for drug delivery } \\
\text { and tissue engineering. }\end{array}$ & [28] \\
\hline
\end{tabular}




\section{Main Properties of Polysaccharide-Based Superabsorbents}

\subsection{Swelling and Absorption Capacities}

As already mentioned, superabsorbents are studied materials for their capacity to absorb and retain water or physical and biological solutions, such as for example urine, electrolyte solution, and blood [7]. Moreover, they present a higher absorption than conventional absorbent materials as they can reach up to thousand times their own dry weight in water for hydrogels without dissolving [6,7]. This incredible property is very interesting for various applications. However, the swelling ability depends on different parameters, such as the type of monomers, the crosslinking density, and other stimuli [11]. The effect of these parameters on the swelling capacity is described later in this review.

There are several steps and mechanisms for the swelling of superabsorbents [32]. The general mechanism for water absorption is explained below. First, water molecules penetrate the polymer network and hydrate the most polar hydrophilic groups, which are generally carboxylates $\left(-\mathrm{COO}^{-}\right)$. Other hydrophilic groups such as alcohol $(-\mathrm{OH})$, amides $\left(-\mathrm{CONH}, \mathrm{CONH}_{2}\right)$, or sulfonic acid $\left(-\mathrm{SO}_{3} \mathrm{H}\right)$ may also be present [9]. Hydrogen bonds appear between these groups and water, they form "primary bound water". After hydration, the polymer network swells and hydrophobic groups interact with water, leading to "secondary bound water". Combined primary and secondary bound water form "total bound water". With polysaccharide, hydroxyl groups $(-\mathrm{OH})$ allow the hydrogen bonds whereas the $-\mathrm{CH}$ ones bring the hydrophobic character [27]. Afterwards, additional water will be absorbed up to the equilibrium swelling level to fill spaces between the network chains and the center of pores or voids. It is called "free water" or "bulk water". This phenomenon is due to the osmotic force of the network, which tends towards infinite dilution and is opposed to physical crosslinking, leading to an elasticity of the network by retraction (Scheme 1) [3,9,23,32].

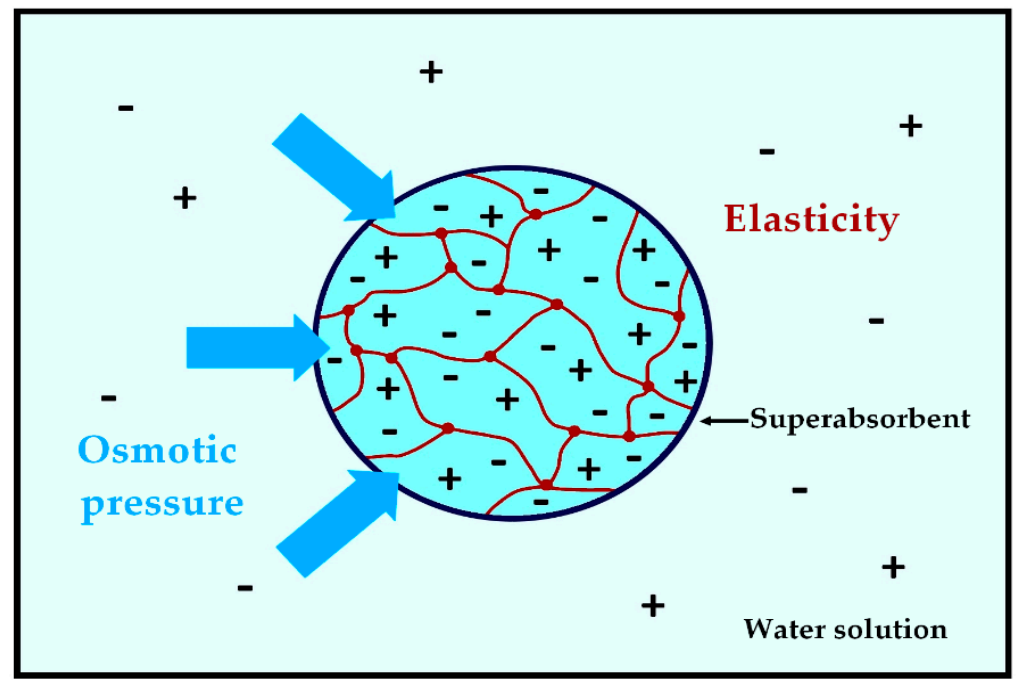

Scheme 1. Illustration of the opposing forces that allow the swelling of the superabsorbent to equilibrium.

For ionic superabsorbents, there are repulsions between negative charges of the polymer chains and neutralization of these charges by positive sodium ions. Additional osmotic pressure will appear within the superabsorbent because of sodium ions, which, once hydrated, will be less attracted to the carboxylate groups. Nevertheless, sodium ions cannot leave the network. As a result, the driving force of the swelling is the difference between the osmotic pressure inside and outside the superabsorbent [22,32].

To measure the amount of fluid absorbed and the swelling property, different methods exist as well as several expressions. In the literature, the expression of the swelling ratio (SR) is the most 
widespread, but it is also known under the names of swelling degree or swelling capacity $[1,9,11,33,34]$. It can be calculated with the Equation (1):

$$
\mathrm{SR}=\frac{W_{s}-W_{d}}{W_{d}}
$$

where $W_{s}$ is the weight of swollen superabsorbent and $W_{d}$ is the initial weight of dry superabsorbent, at a given temperature and time. It is most expressed in grams of water per gram of the superabsorbent $[1,34]$. When the weight of the swollen superabsorbent is taken at swelling equilibrium $\left(W_{s}=W_{\text {eq }}\right)$, the terms of Equilibrium Swelling (Seq), Equilibrium Swelling Ratios (SR), and Equilibrium Degree of Swelling (EDS) are used $[9,33,35]$. It is sometimes expressed as a percentage [35].

Some studies also talk about water retention capacity, which seems to be the amount of water release after reaching swelling equilibrium. It is expressed as a percentage and defined by the Equation (2):

$$
\mathrm{WR}(\%)=\frac{W_{t}-W_{d}}{W_{i}-W_{d}} \times 100
$$

where $W_{i}$ is the initial weight of swollen superabsorbent, $W_{d}$ is the weight of the dry superabsorbent and $W_{t}$ is the weight of the superabsorbent heated at a defined temperature and time. Polysaccharide-based superabsorbents have excellent water retention capacity. A chitosan derivative graft AA SAP has shown good retention capacity. Indeed, $24 \mathrm{~h}$ after reaching swelling equilibrium, it could still retain $71 \%$ of water. To release all the water absorbed, $120 \mathrm{~h}$ were needed. This can be explained by the numerous interactions between water and the polymer (hydrogen bonds and Van der Waals forces) as well as by the compact network structure $[11,36]$.

According to the data from various studies (Table 2), it would appear that polysaccharide-based superabsorbents have a swelling capacity in water, ranging from 110 to $610 \mathrm{~g} / \mathrm{g}$ with a majority around $500 \mathrm{~g} / \mathrm{g}$. However, semisynthetic superabsorbents seem to show better performances with swelling of up to $1500 \mathrm{~g} / \mathrm{g}$ as well as synthetic materials. In general, in the literature, synthetic superabsorbents remain those with the highest values of liquid absorption. Nevertheless, this list is not exhaustive and quite different values can sometimes be found in the literature.

\subsection{Mechanical and Thermal Properties}

Mechanical strength is an important property of superabsorbents for biomedical and pharmaceutical applications such as for tissue engineering, drug delivery, or wound dressing. Indeed, this property allows to maintain the physical form of superabsorbents (especially hydrogels). Studies have shown that it can be increased by increasing the crosslinking density to obtain stronger superabsorbents or on the contrary be decreased by heating [9,37]. However, many superabsorbents, including polysaccharide-based superabsorbents, have weak mechanical properties [9]. They also present poor toughness, limited extensibility, and recoverability and have no effective energy dissipation mechanism [6,11]. To observe the mechanical behavior of superabsorbents, Hooke's law (3) can be used even if applied for elastic solids. It indicates that the strain of a solid is proportional to the applied stress, the proportionality constant being the Young's modulus $[6,36]$.

$$
\sigma=\text { E. } \varepsilon
$$

In Equation (3), $\sigma$ is the applied stress $(\mathrm{Pa}), \varepsilon$ is the strain or the deformation, and $\mathrm{E}$ is the Young's modulus $(\mathrm{Pa})$.

Thermal properties are less known but temperature-responsive superabsorbents exist. They are important for biomedical applications as they can modify their form by a change in temperature. Superabsorbent hydrogels based on cellulose, chitosan, or dextran can be temperature-responsive [9].

In order to increase the number of superabsorbent applications, their thermal and mechanical properties need to be improved. Different approaches have been carried to solve this problem, 
by incorporating specific crosslinkers or with the synthesis of double-network, triblock copolymer, and nanocomposites for example. Differential scanning calorimetry (DSC) and dynamic mechanical analysis are then used to study and characterize mechanical and thermal properties of superabsorbents $[6,11]$.

\subsection{Biodegradability and Biocompatibility}

Unlike the majority of synthetic superabsorbents, most of those with natural origin are biodegradable. This means that these materials can see their three-dimensional structure destroyed by the action of enzymes and microorganisms, the bonds between and inside the polymer chains being broken [9]. Polysaccharide-based superabsorbents researches are notably driven by their biodegradability, which could respond to environmental problems in agriculture and biomedicine fields [11]. Among them, chitosan and starch are the most promising biodegradable polymers [9] after action of chitinases and amylase, which can completely hydrolyze these polymers. Moreover, this property is important when superabsorbents end up being part of water waste and are treated, after use [11].

Biopolymers are often also biocompatible, as they have the ability to be accepted by a host with an appropriate response for a specific application. This induces biosafety without adverse effects $[22,37]$. Chitosan and derivatives, for example, can form superabsorbents with antibacterial properties [11]. In addition, these polysaccharides have shown low toxicity toward mammalian cells [9]. The biocompatibility is very sought in tissue engineering for good interactions with the human body, in order to avoid damage on the connected tissues. This tissue biocompatibility of SAHs can be assessed by cell culture methods or cytotoxicity tests as elution, direct contact, or agar diffusion [37]. 
Table 2. Swelling data of natural, synthetic, and semisynthetic superabsorbents.

\begin{tabular}{|c|c|c|c|}
\hline Type and Name of Superabsorbent & Maximum Swelling in Distilled Water $(\mathrm{g} / \mathrm{g})$ & $\begin{array}{l}\text { Maximum Swelling in } \\
\mathrm{NaCl} \text { Solution }(\mathrm{g} / \mathrm{g})\end{array}$ & Reference \\
\hline Pectin-based superabsorbent hydrogel & 484 & $74(0.05 \mathrm{M} \mathrm{NaCl})$ & [38] \\
\hline Pectin-based superabsorbent hydrogel & 500 & $15(0.9 \% \mathrm{NaCl})$ & [39] \\
\hline Modified cashew-gum with acrylamide & 1500 & 1 & [6] \\
\hline Vinyl-modified starch superabsorbent hydrogel & 150 & / & [6] \\
\hline Starch-based superabsorbent polymers & $\begin{array}{r}\sim 110 \text { (Maize) } \\
\sim 126 \text { (Potato) }\end{array}$ & / & [21] \\
\hline Vinylated Arabic gum superabsorbent hydrogel & 500 & / & [6] \\
\hline Kappa-carrageenan with graft acrylic acid superabsorbent hydrogel & 789 & 1 & [40] \\
\hline Canola protein-based with graft acrylic acid monomers superabsorbent hydrogel & 448 & $\sim 20(0.9 \mathrm{M} \mathrm{NaCl})$ & [41] \\
\hline Cellulose nanofibrils and chitosan-graft-poly(acrylic acid) superabsorbent hydrogel & 486 & 1 & [42] \\
\hline Cellulose-Chitosan crosslinked superabsorbent hydrogels & 610 & $85(0.9 \% \mathrm{NaCl})$ & [43] \\
\hline Hemicellulose-based hydrogel with graft acrylic acid and acrylic amide & 1128 & $132(0.9 \% \mathrm{NaCl})$ & [44] \\
\hline Wheat straw with graft acrylic acid, acrylic amide and dimethyl diallyl ammonium superabsorbent & 133.76 & $33.83(0.9 \% \mathrm{NaCl})$ & [34] \\
\hline Ammonia ethyl chitosan with acrylic acid superabsorbent polymer & 644 & $99(0.9 \% \mathrm{NaCl})$ & [35] \\
\hline Alginate-based superabsorbent hydrogel & 450 & $60(0.9 \% \mathrm{NaCl})$ & [39] \\
\hline Acrylic-based superabsorbent hydrogel & 822 & $66(0.9 \% \mathrm{NaCl})$ & [45] \\
\hline Poly(acrylic acid-acrylamide) superabsorbent & 1019 & $49(0.9 \% \mathrm{NaCl})$ & [46] \\
\hline
\end{tabular}




\subsection{Parameters That Affect Swelling Properties}

Superabsorbents are important for their swelling and superabsorption capacities [19]. However, these properties are influenced by different factors, such as the crosslinking degree and the type of crosslinker or the ionic strength and the composition of swelling solutions [6,31]. In addition, some superabsorbents, called smart, can be sensitive to environmental stimuli, such as variations in temperature, $\mathrm{pH}$, light, or pressure, which can lead to a change in swelling properties [19].

\subsubsection{Physical Stimuli}

Thermo-responsive superabsorbents show a change in volume with shrinkage or swelling behaviors during temperature variations. These materials, especially hydrogels, have a lower critical solution temperature (LCST), which represents the temperature limit where hydrogels undergo a phase transition [29]. Below LCST, SAH is soluble in aqueous solutions and can absorb water. This is due to the hydrophilic groups of the network, which interact with the water molecules by hydrogen bonds, leading to stronger polymer-water interactions than the hydrophobic interactions between polymers. On the contrary, the increase in temperature, beyond LCST, forces the liquid out since the hydrophobic interactions are predominant. SAH is then insoluble and in compact form. Superabsorbent hydrogels with an upper critical solution temperature (UCST) can also exist and stay solid below the UCST.

Many polysaccharides, such as cellulose or dextran, can form smart superabsorbents with thermo-responsive behavior [9,19]. For example, a superabsorbent with AA grafted onto kappa-carrageenan shows a significant increase in water absorption from $50^{\circ} \mathrm{C}$ to $80^{\circ} \mathrm{C}$ with a maximum absorbency of $789 \mathrm{~g} / \mathrm{g}$, and then a decrease with temperature above $80^{\circ} \mathrm{C}$ [40]. Likewise, by varying the temperature from $8{ }^{\circ} \mathrm{C}$ to $37^{\circ} \mathrm{C}$, a thermosensitive pectin-based superabsorbent presents an increase in its swelling capacity with water from $376 \mathrm{~g} / \mathrm{g}$ to a maximum of $484 \mathrm{~g} / \mathrm{g}$. The authors attributed this increase to several factors with temperature, including the flexibility of polymer chains or the diffusion of water molecules in the network [38].

A pressure-sensitive superabsorbent often also has thermo-sensitivity because swelling behavior can be caused by a change in its structure at the LCST under hydrostatic pressure.

Light-sensitive or photoresponsive superabsorbents also exist and can change their properties such as the degree of swelling by photoirradiation. However, they do not have many applications because light cannot penetrate everywhere. For example, in the biomedical field, they can only be used in ex vivo because ultraviolet radiation cannot penetrate tissues.

Finally, superabsorbents sensitive to electric fields are often made of ionic polymers. Indeed, the counter ions of charged groups migrate in the electric field, resulting in the formation of concentration gradient, which modifies the osmotic pressure and causes shrinking or swelling behaviors. This type of superabsorbent can have drug delivery applications [9].

\subsubsection{Chemical Stimuli}

\section{Effect of $\mathrm{pH}$}

In general, $\mathrm{pH}$ can have an important role in the swelling and absorption capacities of superabsorbents. Small variations in the $\mathrm{pH}$ of an aqueous solution can cause a significant change in the size of these materials. These changes are mainly due to the ionic groups of the polymeric network, which can be protonated or deprotonated (ionized) and highly hydrophilic, depending on the $\mathrm{pH}$ of the aqueous medium. Acidic groups, such as carboxylic acid $(-\mathrm{COOH})$ or sulfonic acid $\left(-\mathrm{SO}_{3} \mathrm{H}\right)$ for example, are protonated below their pka $(\mathrm{pH}<\mathrm{pKa})$ whereas basic groups such as amines are protonated when the $\mathrm{pH}$ of the solution is higher than the $\mathrm{pka}(\mathrm{pH}>\mathrm{pka})$. When these groups are ionized (or deprotonated), this leads to increased swelling because of osmotic force. Conversely, when these groups are protonated, the superabsorbent swells little $[9,11]$.

The mechanism of this phenomenon is explained in the case of a superabsorbent with a majority of acidic groups, knowing that it is similar for basic groups but with aqueous solutions of different 
$\mathrm{pH}$. In an acidic medium, (defined for $\mathrm{pH}<\mathrm{pKa}$ ), acidic groups are protonated and strong hydrogen bonds between these groups are present, preventing the swelling of the superabsorbent. When the $\mathrm{pH}$ is higher $(\mathrm{pH}>\mathrm{pKa})$, acidic groups become charged, reducing the hydrogen bonds and reinforcing the electrostatic repulsions between anionic groups. This leads to an affinity increase for water, causing the swelling of the superabsorbent. Nevertheless, in highly basic solutions $(\mathrm{pH}>9)$, counterions, in particular sodium cations $\left(\mathrm{Na}^{+}\right)$, can have a screen effect on the charged groups, resulting in a swelling loss. These counterions are often brought by sodium hydroxide $(\mathrm{NaOH})$ [11]. For cationic superabsorbents, chloride ions $\left(\mathrm{Cl}^{-}\right)$are the main counterions found in acid solutions (low $\mathrm{pH}$ ) [36].

Many authors have noted this mechanism with the study of the effects of $\mathrm{pH}$ on the swelling capacity. For example, a pectin-based superabsorbent sensitive to $\mathrm{pH}$ was studied in buffer solutions with pHs 1.2 and 7.4. In the acidic buffer, the swelling value reaches $22.4 \mathrm{~g} / \mathrm{g}$ because the carboxylic acid groups of pectin are protonated. Contrariwise, with the buffer solution at $\mathrm{pH} 7.4$, these groups are charged $\left(-\mathrm{COO}^{-}\right)$and the electrostatic repulsions provide a maximum swelling of $88.3 \mathrm{~g} / \mathrm{g}$ [38]. Another study on a semisynthetic superabsorbent with AA grafted onto chitosan backbone can be taken as an example. Under $\mathrm{pH} 4$ to 6, most groups are protonated and hydrogen bonds between carboxylic acid and amine groups are formed, leading to swelling less than $350 \mathrm{~g} / \mathrm{g}$. At pH between 6 and 8 , carboxylic acid groups are ionized and there is an increase in the swelling due to electrostatic repulsions, reaching a maximum of about $530 \mathrm{~g} / \mathrm{g}$. Finally, at $\mathrm{pH}$ lower than 2 or higher than 12 , there is a significant decrease in the water absorption capacity because of the screen effect of counterions [36].

\section{Effect of Ionic Strength}

For the majority of superabsorbents, the ionic strength of swelling solutions has a significant effect on their swelling and absorption properties [6]. Indeed, the swelling ratio tends to decrease in saline solution [33] as shown by the data in Table 2. For example, a pectin-based superabsorbent has a maximum absorption of $396 \mathrm{~g} / \mathrm{g}$ with distilled water whereas the swelling ratio has fallen to $74 \mathrm{~g} / \mathrm{g}$ and $47 \mathrm{~g} / \mathrm{g}$ in 0.05 and $0.5 \mathrm{M}$ of $\mathrm{NaCl}$ solution, respectively [38]. This important decrease was often reported in the literature, as for a hemicellulose-based superabsorbent, which exhibited a swelling of $1128 \mathrm{~g} / \mathrm{g}$ in distilled water and then $132 \mathrm{~g} / \mathrm{g}$ in $0.9 \%(w / v) \mathrm{NaCl}$ [44]. Two reasons can explain this phenomenon. Firstly, as mentioned in the previous section, cations provided by salt solutions such as $\mathrm{Na}^{+}, \mathrm{K}^{+}, \mathrm{Ca}^{2+}$ or $\mathrm{Mg}^{2+}$ can cause a charge screening effect of anionic groups in the polymeric network. This leads to a reduction of electrostatic repulsions between anionic groups and to a decrease in the osmotic pressure between the external solution and the superabsorbent. To sum up, increasing the external ionic concentration could lead to a decrease in the swelling of superabsorbents $[9,33,36]$. Moreover, the charge screening effect allows to bring additional ionic crosslinking in the polymeric network, preventing this expansion and reducing the swelling capacity [9].

Other authors have also noted that the size and valence of cations have an influence on the swelling. Divalent and trivalent ions such as $\mathrm{Ca}^{2+}$ or $\mathrm{Mg}^{2+}$ and $\mathrm{Al}^{3+}$ can form stronger complexes with carboxylate ions compared to small monovalent cations such as $\mathrm{Na}^{+}$or $\mathrm{K}^{+}$. Therefore, the swelling capacity is often higher in $\mathrm{NaCl}$ and $\mathrm{KCl}$ solutions than in $\mathrm{MgCl}_{2}, \mathrm{CaCl}_{2}$, and $\mathrm{AlCl}_{3}$ saline ones [11,34]. A superabsorbent hydrogel based on cellulose, showed this effect in $\mathrm{CaCl}_{2}$ and $\mathrm{NaCl}$ solutions. Indeed, the swelling ratio decreased more quickly in $\mathrm{CaCl}_{2}$ solution than in $\mathrm{NaCl}$ one due to the higher ionic strength. Without salts, the swelling ratio was about $1000 \mathrm{~g} / \mathrm{g}$ (for the most efficient superabsorbent) and fell to approximately $225 \mathrm{~g} / \mathrm{g}$ with a $\mathrm{NaCl}$ concentration of $0.1 \mathrm{M}$ and to $100 \mathrm{~g} / \mathrm{g}$ with $\mathrm{CaCl}_{2}$ at the same concentration [33].

In many scientific documents, a salt sensitivity factor $f(4)$ has been defined to evaluate the effect of ionic strength on the swelling capacity. It is described as follows:

$$
f=1-\left(\frac{W_{S}}{W_{W}}\right)
$$


where $W_{S}$ and $W_{W}$ are the swelling capacities in saline solution and deionized water. This factor is dimensionless [42,47].

Effect of Concentration of Monomer and Initiator

Many studies have shown that the concentration of monomers and initiator has an impact on the absorption capacity of grafted superabsorbents.

The initiator is used to initiate the polymerization, in particular for the grafting of monomers onto polysaccharide backbones [44]. Generally, water absorption increases proportionately to initiator concentration until a maximum and then decreases considerably. For example, grafted AA on a chitosan derivative superabsorbent increased its water absorption from 241 to $429 \mathrm{~g} / \mathrm{g}$ when the content of the initiator used (Ammonium persulfate) increased from 0.5 to $2.0 \%$. This can be explained by the insufficient number of active centers when the initiator content was not concentrated enough. Therefore, there were fewer grafting points and the polymeric network was incomplete or unstable, resulting in lower water absorption. Then, the increase in the initiator content made it possible to improve the absorption of water, reaching a maximum with $2.0 \%$ of initiator. However, when the content of initiator continued to increase, it was found in excess and produced more free radicals, which led to a decrease in the water absorption capacity due to shorter chain lengths or the formation of compact networks [36,44].

Regarding grafted synthetic monomers, the increase in their concentration has a similar effect on the water absorption capacity than with the initiator. A hemicellulose-based superabsorbent with grafted AA and amide is a good example of this effect. Indeed, the water absorption increased with the raise of AA content and reached a maximum of $997 \mathrm{~g} / \mathrm{g}$ (for $15 \mathrm{~g}$ of AA). After this point, the absorption decreased. AA monomers allow providing hydrophilic groups, which are important for absorption mechanism but when the content was too high, the network was compacted because of excessive crosslinking. With increasing hemicellulose content, there was an increase in water absorption and then a decrease too, but the maximum was reached with only $1 \mathrm{~g}$ of hemicellulose. The main reason seems to be that carboxylic acid groups of AA are the main groups for water absorption. As a result, less hemicellulose is used, the easier it is to graft more AA monomers and the greater the water absorption capacity [44].

\section{Effect of Neutralization}

Neutralization with alkaline solutions of anionic charges of AA grafted polymers impact their swelling capacities [32,40]. In most cases, the swelling capacity increases with the neutralization degree [32]. The swelling and absorption capacities are associated with the electrostatic repulsions of carboxylates and their affinity to water. When there is no neutralization step, carboxylic acid groups are protonated, there is no repulsion between these groups and the water absorption capacity is low [40]. However, when AA monomers are neutralized by $\mathrm{NaOH}$, these groups are charged and allow an increase of swelling due to repulsive forces. With a high neutralization degree, the swelling capacity tends to decrease because of screening by sodium ions, which was explained in the previous sections [41]. As an example, the hemicellulose grafted with AA shows an increase in swelling capacity with a neutralization degree from $65 \%$ to $75 \%$ and reaches a maximum of $1100 \mathrm{~g} / \mathrm{g}$. Further increase in the neutralization degree leads to a decrease in water absorption to less than $800 \mathrm{~g} / \mathrm{g} \mathrm{[44].}$

\section{Effect of Crosslinker and Crosslinking Density}

The crosslinking density is a key factor for swelling variations. It can significantly influence the swelling ratio but also the mechanical properties. It depends on the type and concentration of crosslinking agent, used to form the three-dimensional network [9]. Generally, the swelling of superabsorbents is inversely proportional to the crosslinking density and, therefore, to the elastic modulus [31]. In other words, increasing the crosslinking density decreases the swelling capacity and increases the resistance of the gel [23]. More precisely, the increase in the concentration of the crosslinker 
leads to higher crosslinking density. Therefore, there is a decrease in the space between chains of the polymeric network and the structure of superabsorbent is tighter and more stable. The elasticity of the network decreases and water molecules have more difficulty to enter the three-dimensional structure, resulting in a low swelling and absorption capacity $[7,40,48]$. Nevertheless, when there is insufficient crosslinking, superabsorbent material can partially dissolve in aqueous solution and lose its absorption capacity [15]. A hemicellulose-based superabsorbent hydrogel can be taken as example of this phenomenon. With this material, the water absorption increased quickly to a ratio of crosslinker ( $\mathrm{N}, \mathrm{N}^{\prime}$-methylenebisacrylamide) to monomer of $0.03 \%(w / w)$. A maximum point with a swelling ratio of $1128 \mathrm{~g} / \mathrm{g}$ was reached and then the swelling decreased to below $600 \mathrm{~g} / \mathrm{g}$ with higher crosslinker content. A similar effect was observed with the absorption of saline solution but with a maximum absorption of $132 \mathrm{~g} / \mathrm{g}$ [44].

A relationship between swelling and the concentration of crosslinker exists and it is defined by the Equation (5):

$$
\text { Swelling }=k \cdot \mathrm{C}_{\mathrm{C}}^{-\mathrm{n}}
$$

where $k$ and $\mathrm{n}$ are specific constants for each superabsorbent and $\mathrm{C}_{\mathrm{C}}$ is the concentration of the crosslinking agent [40].

\section{Preparation and Synthesis of Polysaccharide-Based Superabsorbents}

\subsection{Components and Material}

The synthesis of SAPs from polysaccharides is little reported by commercial manufacturers. Sanyo Chemical was the first to market a SAP in 1978. It was polymerized from AA, then crosslinked and grafted onto starch. Then, a neutralization step took place, followed by drying and grinding [49]. However, more descriptions are available for SAHs. It has been generally described that the preparation of hydrogels requires monomers or polymers, an initiator, and a crosslinking agent [25].

Nevertheless, there is some confusion among the authors in regard to the terms monomers and polymers as well as polymerization and crosslinking. The definitions of the reference organization for chemical nomenclature (CIUPAC, iupac.org) will then be preferred. For SAP synthesis, we will talk about polymerization, which IUPAC described as "the process of converting a monomer or a mixture of monomers into a polymer" [50]. Moreover, the monomer molecule is described as "a molecule, which can undergo polymerization thereby contributing constitutional units to the essential structure of a macromolecule" [50]. Whereas for the preparation of SAHs, which are three-dimensional networks [11], we will speak rather of a crosslinking of polymers. These two terms being defined as "reaction involving sites or groups on existing macromolecules or an interaction between existing macromolecules that results in the formation of a small region in a macromolecule from which at least four chains emanate" for crosslinking and as "a molecule of high relative molecular mass, the structure of which essentially comprises the multiple repetition of units derived, actually or conceptually, from molecules of low relative molecular mass" for polymer or macromolecule $[17,50]$. Since polysaccharides are already polymers, only the synthesis of SAHs by crosslinking will be discussed in detail in the second section. The polymerization process will only be mentioned when monomers are grafted to a crosslinked polymer network.

To produce polysaccharide-based SAHs, different crosslinking mechanisms can take place. In all cases, polysaccharides must be present and constitute the raw material [11]. These polymers can be crosslinked to each other or with other polymers and molecules by their functional groups (like hydroxyl ones). A crosslinking agent, also called crosslinker, is then necessary in order to create the polymeric network. In the literature, the most reported crosslinker for polysaccharide-based SAH production are $\mathrm{N}, \mathrm{N}^{\prime}$-methylenebisacrylamide, glyceraldehyde, formaldehyde, epichlorohydrin, and adipic dihydrazide $[9,18]$. The third widely used material is the initiator, which occurs during polymerization of monomers on polysaccharide backbones by grafting. Ammonium persulfate, sodium persulfate, and potassium persulfate are the most used initiators. For grafting, synthetic monomers such as 
AA, acrylamide, or methacrylamide can be required [11]. For example, AA monomers were grafted onto kappa-carrageenan with ammonium persulfate as initiator and $\mathrm{N}, \mathrm{N}^{\prime}$-methylenebisacrylamide as crosslinker [40].

Finally, aqueous solutions can be used as diluents and washing solutions are useful to remove impurities [25]. Moreover, if the neutralization step needs to be done during superabsorbent synthesis, a neutralizing agent such as sodium hydroxide will have to be added [32].

\subsection{Crosslinking Methods}

In order to produce SAHs, polysaccharides can be chemically or physically crosslinked (Figure 3). With chemical crosslinking, strong covalent bonds are present between polymer chains to produce irreversible and stable superabsorbents, which are able to resist changes in the external environment. This type of SAH has good mechanical strength and longer degradation time but the toxicity of some crosslinkers can be problematic for some applications [9,11]. On the contrary, physical crosslinking allows obtaining reversible SAH in which polymers are linked by secondary forces, such as ionic or hydrophobic interactions as well as hydrogen bonding. This type of crosslinking does not need a crosslinker but the stability of physical SAH depends on external variations [18]. Several crosslinking methods exist to synthesize chemical or physical SAHs [11].

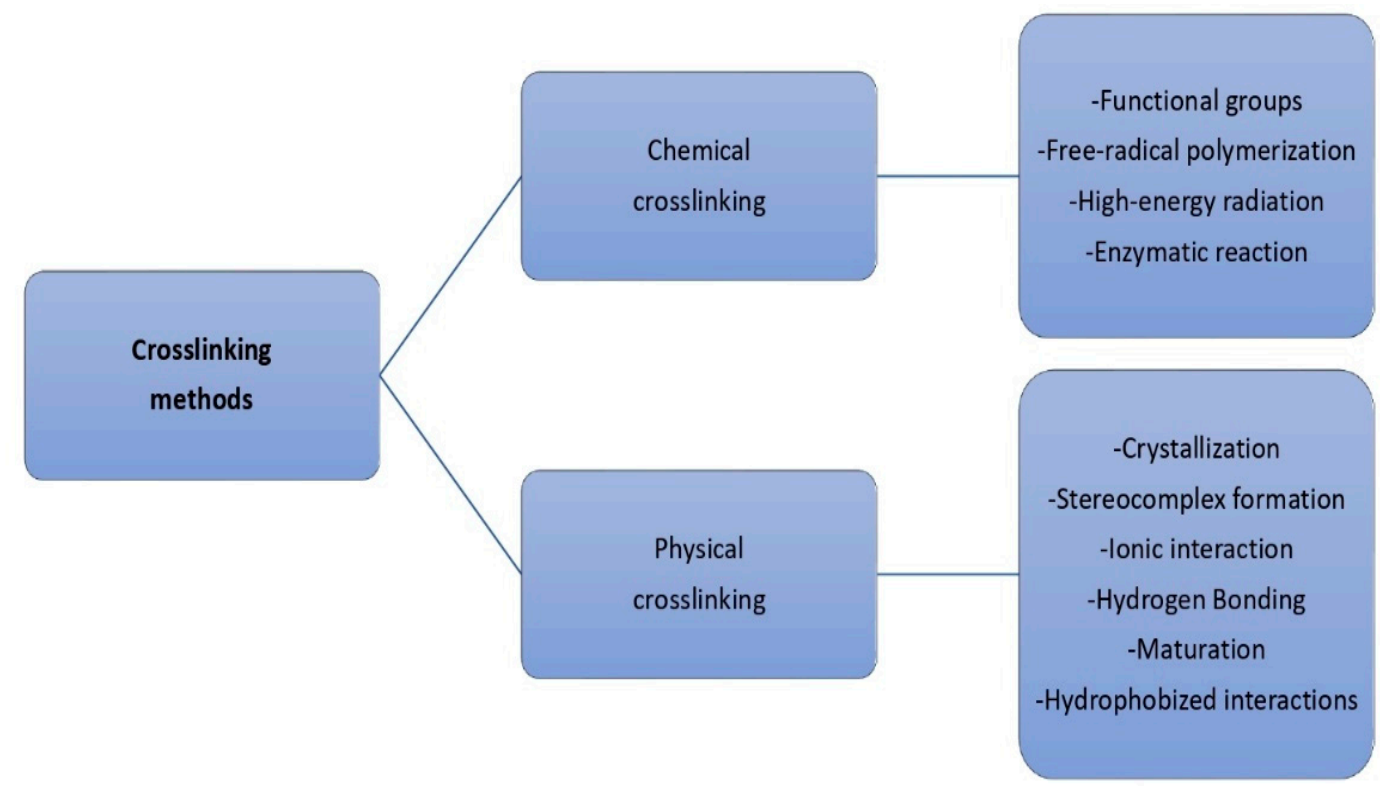

Figure 3. Crosslinking methods to produce a polysaccharide-based superabsorbent.

\subsubsection{Chemical Crosslinking}

Different chemical crosslinking methods can be used for the synthesis of polysaccharide-based SAHs. The reported mechanisms are crosslinking by functional groups, free-radical polymerization, high-energy radiation, and enzymatic reaction [9].

Polysaccharides have functional and hydrophilic groups such as carboxylic acids $(-\mathrm{OOH})$, amines $\left(-\mathrm{NH}_{2}\right)$ or hydroxyl groups $(-\mathrm{OH})$, which can be chemically crosslinked by a crosslinker to create SAHs $[9,18]$. Three mechanisms use these groups: Schiff-base, Michael addition, and condensation reactions. Amine groups present in polysaccharides can react with aldehydes or dihydrazide as crosslinkers to form Schiff-bases and then SAHs. Glutaraldehyde and adipic acid dihydrazide are the most used for crosslinking. They work at a high temperature, low $\mathrm{pH}$, and with the addition of methanol to create imine group (Schiff-base). For example, amines of modified hyaluronic acid can react with aldehyde groups of polyethylene glycol propionaldehyde to form hydrogel. The Michael addition rather reacts a nucleophile function of a polymer, such as amine or thiol groups, with an electrophile such as 
vinyl or acrylate groups on another polymer to produce SAHs. Hyaluronic acid, dextran, and chitosan are among the polysaccharides used for Michael addition. Finally, condensation reactions can take place between hydroxyl or amine groups with carboxylic acids or its derivatives to form ester or amide bonds. Slightly acidic water and room temperature are necessary for these reactions. The crosslinking agents used are N,N-(3-dimethylaminopropyl)-N-ethyl carbodiimide and N-hydroxysuccinimide [9,51].

Free-radical polymerization is another chemical crosslinking method, which is frequently used for the synthesis of superabsorbents [19]. This technique involves grafting synthetic monomers onto polysaccharide backbones by the presence of a crosslinker, often $\mathrm{N}, \mathrm{N}^{\prime}$-methylenebisacrylamide [11]. The polymerization begins with initiators, which can generate free radicals from polysaccharides. Heating or using a redox system are other ways to create these radicals. Then, radicals will be able to react with synthetic monomers to produce chain propagation. At the same time, the crosslinker allows to create polymeric networks. Acrylic derivatives such as vinyl monomers as well as hyaluronic acid, dextran, and chitosan among polysaccharides are the most used. Free-radical polymerization can take place in emulsion, bulk, suspension, or solution $[1,9,11]$.

In high-energy radiation, free radicals can be also formed in polysaccharide chains by gamma rays or electron beam. However, this technique does not involve the use of crosslinker and occurs at room temperature. When the crosslinking performs in an aqueous solution, the water molecules absorb the radiation to generate radicals, which will activate the polysaccharide backbone. Although polysaccharide-based SAHs are generally crosslinked in an aqueous solution, the irradiation can also take place in a concentrated solution or in a solid state. For example, Arabic gum, carboxymethyl cellulose, and dextran have been crosslinked by high-energy radiations in a solid state to produce SAH $[9,18]$.

The last chemical method is enzymatic reaction. In this technique, enzymes are used to create crosslinking points between polymer chains. The main advantages are that the enzymes are specific to a given substrate and their use makes it possible to eliminate side reactions during crosslinking. On the contrary, some enzymes are unstable and their use leads to the formation of SAHs with low mechanical strength. Transglutaminase and horseradish peroxidase are examples of enzymes used to crosslink natural polymers such as chitosan and alginate [9,31].

\subsubsection{Physical Crosslinking}

For physical crosslinking, the methods used for polysaccharide-based SAHs are the crystallization, stereocomplex formation, ionic interaction, hydrogen bonding, maturation, and hydrophobized interactions [9].

Crosslinking by crystallization is mainly used for thermosensitive SAHs, which can change shapes with temperature variations. Indeed, at room temperature, double helices form as well as crystallites (small crystals). The aggregation of formed helices and crystallites leads to the formation of junction points. These points act as crosslinking points to create the polymeric network. This process is called freezing-thawing and is usually repeated several times for the crystallization method. The formation of SAHs by this method has been reported for chitosan, cellulose, and dextran $[9,22,52]$.

Another physical crosslinking technique is the formation of a stereocomplex. It is based on interactions between polymers of different chirality in order to constitute a stereocomplex. With this method, SAHs can be easily obtained by dissolving each polymer in an aqueous solution at room temperature and by mixing the solutions. An example of dextran with grafted lactic acid oligomers has been reported to form hydrogel. However, this method is limited by the few polymers possessing stereocomplex properties $[9,18,31]$.

Ionic interactions between two polymers of opposite charges (polyelectrolytes) can form SAHs too. It can also take place between a charged polymer and a molecule of opposite charge or a multivalent ion. In all cases, these polymers can be crosslinked at room temperature and physiological $\mathrm{pH}$. For example, alginate can be crosslinked with calcium ions, like chitosan with glycerol-phosphate disodium salt, or even carrageenan with potassium ions. 
Hydrogen bonding is also possible due to the presence of functional groups of polysaccharides. Crosslinking by hydrogen bonding can be achieved between two polymers or between a polymer and an acid or a polyfunctional monomer. Cellulose, alginate, and chitosan are polymers, which can easily form hydrogen bonds with their hydroxyl, carboxyl, and amine groups. As example, a mix of starch and carboxymethyl cellulose with intermolecular hydrogen bonding has been reported $[9,18]$.

Some natural polymers can be crosslinked to create a network by maturation, also called heat-induced aggregation. In this method, a thermal treatment makes it possible to aggregate the protein components present in polysaccharides. That allows the increase in molecular weight and the formation of SAH. The use of Arabic gum with this method is a good example among polysaccharides [9]. However, this method is one of the least used among the physical crosslinking methods.

The last method of physical crosslinking is based on hydrophobic interactions. These interactions are created between hydrophobic blocks of polymer backbones in aqueous solution. Among polysaccharides, crosslinking by hydrophobic interactions can take place with chitosan or dextran, for example [9,31].

\section{Techniques for Characterizing a Superabsorbent}

\subsection{Swelling Measurements}

To characterize the swelling capacity of superabsorbents, several techniques exist. They are almost all based on the measurement of volume or mass changes. The two most commonly used and useful methods are the tea bag and the filtration [1].

In the tea-bag method, the dry superabsorbent is weighed and placed in a tea bag with fine meshes and with a known mass. The bag is immersed in distilled water or an aqueous solution at room temperature until reaching the swelling equilibrium. Then, the bag is removed from the solution and hung up to remove excess liquid. When no drops fall, a paper towel or a dry cloth can be used to remove the free water from the bag. The bag is weighed and the equilibrium swelling ratio can be calculated [21,53].

For the filtration method, the dry superabsorbent is placed in a funnel with filter paper. An aqueous solution is added and the superabsorbent is then filtered under vacuum until no more drops fall. The amount of filtered liquid is measured. In order to prevent the filter paper from influencing the measurement, it was saturated with the aqueous solution before filtration. Similarly, a lid can be placed on the filter to prevent the evaporation of the fluid during the process. The mass of the swollen superabsorbent can be measured by the difference between the added water and the filtered water $[1,54]$.

These two methods are gravimetric methods (based on mass measurements) but others such as Differential Scanning Calorimetry (DSC) or Nuclear Magnetic Resonance (RMN) can also be performed to measure the swelling capacity $[1,9]$.

\subsection{Fourier Transform Infrared Spectroscopy (FTIR)}

FTIR is one of the most widely used characterization techniques for superabsorbents. This is a qualitative technique, based on the absorption of infrared radiation by the material. The energy associated with these absorptions corresponds to the vibrations of the chemical bonds of the polymeric network. As a result, by measuring the amount of light absorbed by a sample as a function of the emitted wavelength, an absorption spectrum with peaks can be obtained. The wavelength is presented as wavenumbers, expressed in $\mathrm{cm}^{-1}$. Spectra are generally recorded in the range of $4000-600 \mathrm{~cm}^{-1}$. The peaks provide information about the chemical groups present in the superabsorbent. Thanks to the appearance or disappearance of certain peaks, it is then possible, for example, to know if the network crosslinking or chemical modifications have worked well. The name of this technique is based on the use of a Fourier transformation to convert the data obtained at all frequencies and return them to usable data $[9,19,23,31]$. 


\subsection{Thermogravimetric Analysis (TGA)}

TGA is a technique used to study the thermal stability of superabsorbents. It allows seeing the weight loss of superabsorbents as a function of temperature. This loss is followed until complete degradation of the sample under an inert or oxidizing atmosphere. This analysis mainly gives information on the degradation temperature of the material studied $[18,19,22]$. Generally, the material is heated under a nitrogen atmosphere at a rate of $10^{\circ} \mathrm{C} / \mathrm{min}$.

\subsection{Differential Scanning Calorimetry (DSC)}

DSC also allows to characterize thermal properties of superabsorbents. In addition, free water in the material after swelling can be measured by this technique. For that, the swollen superabsorbent is frozen and then warmed [6]. Only free water is supposed to be able to be frozen. Therefore, when the temperature of the swollen and frozen material increases, the observed endothermic peak is representative of the melting of free water. Bound water present in the superabsorbent can then be calculated by the difference between free water and total water measured by TGA [11].

\subsection{Scanning Electron Microscopy (SEM)}

The SEM is a technique used to study the morphology, the porosity, and the structure of superabsorbents [9]. SEM provides precise information, such as pore size and distribution. Moreover, the morphology is very important to understand absorption and swelling capacities [6]. This is a quantitative analysis method, consisting of scanning the surface of a sample with an electron beam. When electrons in the incident beam interact with atoms of the sample, low-energy secondary electrons emerge from the surface. These electrons constitute signals, which once detected, makes it possible to obtain images with high resolution. The initial electron beam being generated by an electron gun $[19,23]$. However, for a good analysis, the sample needs to be prepared in specific conditions. For example, to preserve the morphology of SAH after swelling, they can first be swollen until equilibrium in an aqueous solution. After freezing in liquid nitrogen, they can be freeze-dried. Then, the sample can be analyzed by SEM [6].

\subsection{Absorbency under Load (AUL)}

AUL is used to measure the resistance of a swollen SAH and its ability to absorb saline solution when subjected to a load. It is important for applications in agriculture because soil load would affect the absorption capacity of superabsorbents. Therefore, this parameter is of great industrial interest. AUL is measured by the following expression (6):

$$
\operatorname{AUL}(\mathrm{g} / \mathrm{g})=\frac{W_{2}-W_{1}}{W_{1}}
$$

where $W_{1}$ and $W_{2}$ are respectively the weights of dry and swollen superabsorbents at a given time. To calculate the value of AUL, a device consisting of a porous sintered glass plate with filter paper on top can be placed in a petri dish. A sample of dry superabsorbent is placed evenly on the surface of a cloth or gauze, which is on the sintered glass. The desired load is applied by a piston, which can slide in a glass cylinder until the surface of cloth or gauze. Then, a saline solution $(0.9 \% w / v \mathrm{NaCl})$ is added to the petri dish at the same height as the filter. The entire device can be covered to prevent evaporation of the solution. At a given time, the swollen sample can be weighed to calculate AUL [23,55].

\subsection{Other Techniques}

Other techniques are used to characterize superabsorbents, especially SAHs. There are X-ray diffraction (XRD), X-ray photoelectron spectroscopy (XPS), and Nuclear Magnetic Resonance (NMR).

The crystalline structure of superabsorbents with the arrangement of polymer chains can be studied by XRD. Small or wide-angle X-ray scattering modes are possible for X-ray analysis $[6,9,56]$. 
In general, this technique is based on the diffraction of an X-ray beam by a crystal lattice. By measuring the diffraction angles, information can be obtained about the crystalline structure of the material. Diffraction profiles with characteristic peaks can be obtained. Polysaccharides can have crystal regions in their structure that have been formed by hydrogen bonds. As a result, XRD can be used to analyze them [48,57]. XPS is a technique close to XRD but that is based on the emission of photoelectrons. It is also used to study the sample composition of superabsorbents [48].

NMR can also provide more precise data for the analysis of molecular structures. This technique allows, for example, determining the efficiency of crosslinking or grafting of monomers onto polymers as well as chemical modifications of their structures. NMR is based on the rotation of atomic nuclei possessing nuclear spins. By applying a magnetic field, the spins orient themselves and have two different states $\alpha$ and $\beta$. The energy difference between these states produces a signal. ${ }^{13} \mathrm{C}$ and ${ }^{1} \mathrm{H} N M R$ are the most employed for the study of superabsorbent, but ${ }^{1} \mathrm{H}$ allows faster data acquisition $[6,19,31,48]$.

\section{Applications}

Polysaccharide-based superabsorbents found many applications in hygiene products but also in biomedical, agriculture, building, and water treatment (Figure 4) [11]. These applications are described below. Nevertheless, a distinction will be made at best between potential and actual applications. Scientific papers often present the potential applications of superabsorbents under development. It is also important to specify that the patents used as examples result from a patent application or grant without knowing whether the patented superabsorbents have been exploited or marketed. Generally, SAPs are mainly produced by Japanese companies such as Nippon Shokubai, Sumitomo Seika Chemicals, and SDP Global, but also by BASF and Evonik, two German manufacturers that have subsidiaries worldwide. These companies alone represented approximately $70 \%$ of the global SAP market in 2015 (www.researchinchina.com). However, it is not always easy to find information on the use of natural polymers as superabsorbents.

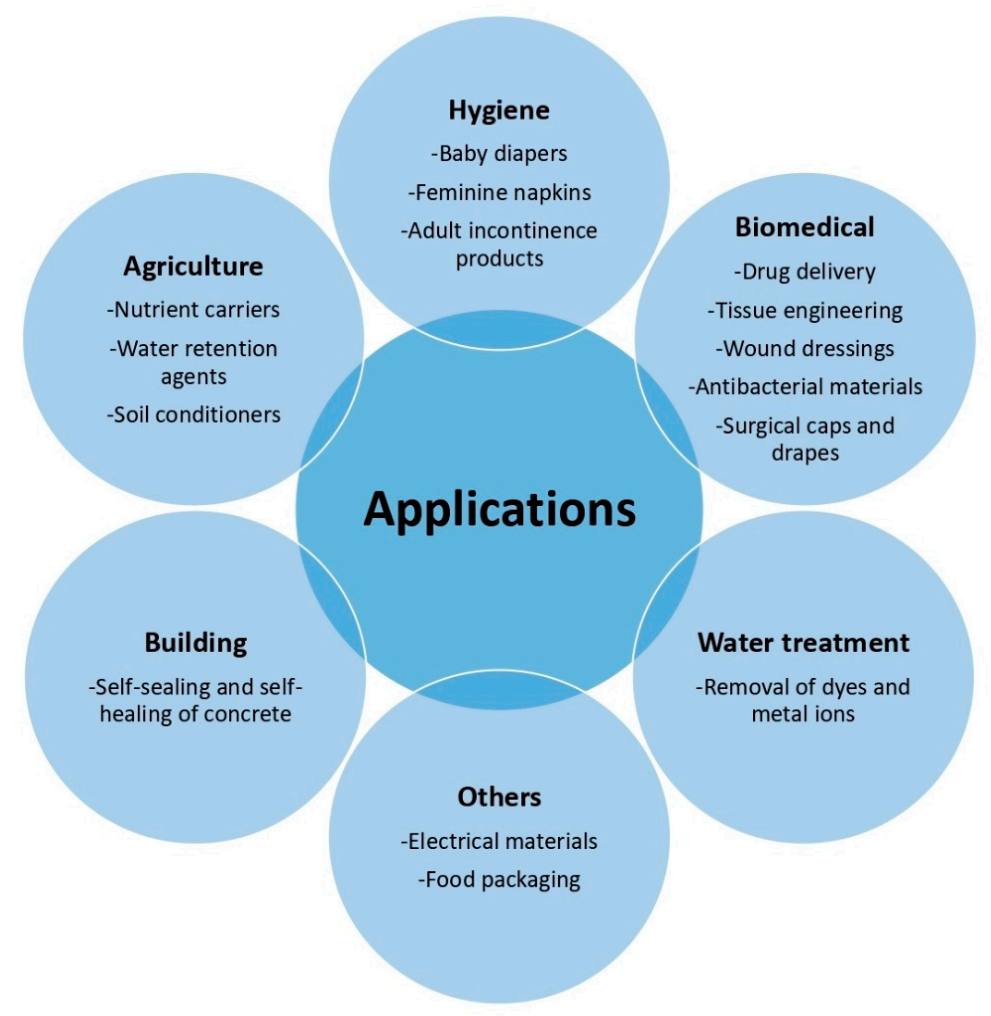

Figure 4. Potential and actual applications of polysaccharide-based superabsorbent. 


\subsection{Hygiene Products}

Superabsorbents can be used for many applications, but since the 1980s they have been mainly marketed for personal hygiene products [11]. Indeed, with a world production of SAP, which exceeded one million tons in 1990, 81\% were intended for baby diapers, followed by adult incontinence products $(8 \%)$, feminine napkins (5\%), and other healthcare applications [54]. In recent years, $80 \%$ of the SAH production was dedicated to personal care products for their ability to absorb urine and blood $[7,10]$.

Regarding disposable diapers, their use has greatly increased since the appearance of Pampers diapers designed by the multinational Procter \& Gamble in 1961. This growth has allowed the improvement of the design of diapers, notably the introduction of SAPs in the 1980s with a commercialization in France and Germany [58,59]. Since the 1990s, disposable diapers have been used in both developed and developing countries [58]. Currently, disposable diapers are made up of three layers. A permeable, nonwoven outer layer, an absorbent core with cellulose pulp with SAP, and an impermeable bottom layer. The top and bottom layers are composed of polypropylene or polyethylene [59]. The use of SAP in powder form allowed a better capacity of absorption and retention of liquid within the diaper core, contrary to traditional materials such as wood pulp, cellulose, or cotton fibers $[59,60]$. Moreover, by preventing leaks, SAP helps prevent diaper rash and control the spread of germs in the event of fecal contamination in play areas [61]. However, the urine absorbed contains ions, in particular sodium ions $\left(\mathrm{Na}^{+}\right)$, which reduces the swelling capacity of superabsorbents compared to pure water. As a result, baby diapers contain up to $15 \mathrm{~g}$ of SAP while $5 \mathrm{~g}$ is enough to absorb one liter of pure water. Traditionally, $0.9 \%(w / v) \mathrm{NaCl}$ solution is used to simulate urine, to test the absorption capacity of SAPs in diapers [23]. AUL is also studied to know the stability of superabsorbent and its resistance to the weight of the baby in order to avoid leakages [58].

Despite the many advantages of superabsorbents used, they are mostly synthesized from vinyl monomers and not biodegradable. A child produces an average of $1092 \mathrm{~m}^{3}$ of waste per year from disposable diapers, which is a significant volume. Therefore, modern industry is now concerned with finding biodegradable superabsorbents [11,62]. For example, the use of hydroethylcellulose and sodium carboxymethylcellulose crosslinked with Divinylsulfone has been suggested to create biodegradable SAHs [61]. In addition, in recent years, numerous patents have been released for the design of diapers [60]. Among them, Lysac Group Inc. published a patent on a superabsorbent with carboxymethylcellulose and/or gums that can be used for diapers [63].

The evolution of feminine hygiene products was quite similar to that of disposable diapers with a first product based on starch-graft-polyacrylate marketed in 1978. Consumers expressed the need to feel clean and dry while being comfortable. For menstrual protection, pads with top sheets were used to convey the liquid to the core containing SAP. These products helped to minimize leaks while controlling odors. In recent years, these old products have been replaced by disposable products, such as internal tampons, sanitary napkins, or panty shields. These new products use nonwoven sheets and SAPs, as for baby diapers. Therefore, many synthetic and natural superabsorbents have been developed to improve this application. However, the production of polysaccharide-based superabsorbents for hygiene products is not yet very widespread [11,58].

\subsection{Biomedical Applications}

Due to their high swelling, biocompatibility, and hydrophilic properties, superabsorbents have features close to living tissues, which make them suitable for many biomedical applications $[7,11]$. Among them, applications in drug delivery, tissue engineering, wound dressing, and as antibacterial materials have been reported $[33,58,64]$. The first use of superabsorbent in the biomedical sector was for contact lenses. A SAH based on poly(hydroxyethylmethacrylate) was developed in the 1950s and patented in 1960 to produce soft contact lenses. Despite its low water absorption capacity of $80 \mathrm{~g} / \mathrm{g}$, unlike modern $\mathrm{SAH}$, its production has allowed the development of other superabsorbent materials [58,61]. 
Superabsorbents have been used in drug delivery systems to prolong the retention of drugs in the intestine or stomach. When they are in gel form, they can easily introduce drugs into the body through the ocular, peroral, vaginal, transdermal, or rectal routes. Due to their retention capacity, controlled release of the drugs can occur over a long period of time. Two different mechanisms are used to release drugs into body fluids. The drug can be released as small molecules after the swelling of hydrogel or SAH can break down in the organism and diffuse the drug $[11,58]$. Polysaccharide-based SAHs with $\mathrm{pH}$ sensitive behavior have been developed for potential applications in controlled drug delivery. Chitosan and alginate have been used alone or with synthetic graft polymers to produce such hydrogels [11,62]. In addition, other SAHs based on methylcellulose or dextran were reported, for the release of thermosensitive drugs or for chemotherapeutic use, respectively [9].

Synthetic and natural SAHs could also be used for tissue engineering. It is their biocompatibility and their permeability to different metabolites that make them suitable materials for this type of application. Indeed, they can form specific cell matrices for rapid cell growth to improve or replace tissues and organs. The most used polysaccharides are hyaluronic acid, agarose, chitosan, and alginate. These polymers can form hydrogels that could be used as scaffolds and especially when they are combined with biological molecules [11,58]. A crosslinked alginate-acrylamide hydrogel can help produce chondrogenic cells when a photochemical treatment is applied to the gel. Semi-interpenetrating networks formed from hyaluronic acid and synthetic acrylate compounds are compatible with mouse cell fibroblasts and exhibit improved cell adhesion [11]. Hyaluronic acid is also used for cartilage regeneration in the human body [9].

Wound dressings for treating burn and chronic wounds such as bedsores or ulcers are another biomedical application for superabsorbents. Indeed, SAHs are very flexible and the associated dressings can be applied and removed easily. In addition, they ensure a good capture of moisture, which creates a humid environment and, thus, allow cell proliferation. Therefore, SAHs are used in wound dressings for skin regeneration [11,58]. Alginate, cellulose, and hyaluronic acid are considered for wound healing applications [9]. However, other polysaccharide-based superabsorbents with starch or chitosan have been patented by several companies, including MedTrade Products Limited [65,66]. Among marketed products, the Purilon ${ }^{\circledR}$ gel developed by Coloplast (https://www.coloplast.ca/) can be cited since it is composed of carboxymethylcellulose and alginate for application to dry wounds and necrotic tissues.

Biodegradable and biocompatible SAHs have also been studied for their antibacterial properties. Chitosan hydrogels for example, have good biocidal activity against some bacteria species thanks to the positive charge of quaternary ammoniums, which attract negative charges from microbial membranes, causing damage to the cell membrane [11].

Finally, the combination of superabsorbents with nonwoven composite materials can be used to surgical caps and drapes. This can provide an impermeable structure to bacteria to protect patients during surgery. The superabsorbent allowing the absorption of fluids that could flow such as secretions from wounds or body perspiration [58].

\subsection{Agriculture Applications}

Agriculture is one of the sectors that make great use of superabsorbents, just after the biomedical and hygiene fields. These materials are mainly present as nutrient carriers, water retention agents, and soil conditioners [15]. Superabsorbents have seen their interest in this sector in order to reduce water consumption, especially in arid and desert areas where water resources are scarce. These materials help grow plants when they are introduced close to the roots in the soil. Indeed, SAH can be loaded with nutrients such as fertilizers that are useful for crops. During irrigation or rain, the water is absorbed by hydrogel. The swelling creates a moisture gradient between the inside and the outside of the SAH, which activates the release of nutrients by diffusing them into the soil. This slow release is stopped when the hydrogel becomes dry again but can be reactivated with watering of the soil. This keeps the soil moist for a long time and saves irrigation water, which can be reused for other applications after evaporation and drainage $[11,61]$. Therefore, these resources are fully used, 
making the use of superabsorbents economical and environmentally friendly [62]. Other benefits of using superabsorbents have been cited, such as increased soil aeration and microbial activity, improving the efficiency of fertilizer and avoid contamination of underwater sources [11].

Biodegradable polymers such as polysaccharides are used to form SAHs with applications in agriculture. They have many advantages, such as their abundance, renewability, and biodegradability as well as their low cost. Their degradation by microorganisms allows in particular breaking down the associated hydrogels in order to release nutrients. In the literature, several authors have developed polysaccharide-based SAHs with starch, chitosan, cellulose, chitin and Arabic gum for fertilizers, and water release [6]. For example, sodium alginate SAH with grafted poly(acrylic acid) was synthesized to release sodium humate, which can accelerate root development and regulate plant growth. This hydrogel presented a high-water absorption capacity of $1380 \mathrm{~g} / \mathrm{g}$ [67]. Other authors developed SAHs with double-layer coating to control release fertilizer and water absorbency. Ethylcellulose or chitosan were used for the inner coating and starch or poly(acrylic acid-co-acrylamide) were used as outer coating. The core being the fertilizer [21,62].

Nanocellulose-based SAHs or nanocomposite hydrogels with nanocellulose have also received interest in recent years for applications in agriculture. Nanocellulose are classified into several categories: cellulose nanofibrils (CNFs), cellulose nanocrystals (CNCs), and bacterial nanocellulose. CNFs are composed of filamentous fragments with amorphous and crystalline domains while CNCs are made up only of crystalline domains but all nanomaterials have a size between $10^{-9}$ to $10^{-6} \mathrm{~m}$. Nanocomposite hydrogels and nanocellulose-based SAHs present good properties as biocompatibility and biodegradability but they are mainly used for their ability to retain water and nutrients as well as the controlled release of these elements, making them good materials as soil amendments. They could then increase crop yields and reduce water and fertilizer inputs [68-71]. A study on superabsorbent nanocomposites with polyacrylamide and carboxymethylcellulose enhanced with calcium montmorillonite was conducted for nutrient release. This material exhibited water absorption up to 5000 times its own weight [72]. Other researchers reported the use of nanocomposites based on polyacrylamide and $\mathrm{CNC}$, which could absorb 600 times its weight in water and for an application as a soil conditioner [73].

Several companies around the world have filed patents for superabsorbents based on polysaccharides. For example, BASF published a patent for a superabsorbent composed of crosslinked polysaccharide and wood flour or other lignocellulose material for soil treatment products [74]. Absorbent Technologies Inc. developed a starch-based SAP with liquid fertilizer solution to form a flowable suspension for soil amendments application [75]. An Italian company, Materias S.R.L. produced a superabsorbent aerogel with starch and cellulose derivatives for use in agriculture. This water absorption reached $500 \mathrm{~g} / \mathrm{g}$ [76]. Moreover, other companies have been able to market superabsorbent products for this sector. For example, an American company named MJJ Technologies is specialized in the development and commercialization of starch-based SAPs for liquid management in agriculture. These superabsorbents constitute soil amendments to improve plant growth and reduce the amount of water used. TryEco ${ }^{\circledR}$ LLC, another company, designed and developed novel patented starch-based SAPs. It created several products such as Agrisorb ${ }^{\circledR}$ or Turf Defender for water conservation in soil but they no longer seem to be marketed. Most of the products marketed of this type have shown some efficiency in saving water. However, it is necessary to avoid overusing these products because their high-water retention capacity makes them potentially dangerous products for crops [61].

\subsection{Water Treatment}

Water pollution is one of the most important environmental issues facing society today. According to the World Health Organization, around 14,000 deaths per day are a result of this problem, particularly in developing countries [11]. The development of industry is the main cause of water pollution. In fact, the textile and colored paper industries discharge wastewater, which contains 
dyes and metal ions in large quantities, which are toxic to humans and the environment $[9,61,77]$. Currently, pollutants are not effectively removed from water because the materials used have low absorption capacities and are not biodegradable [11]. Therefore, superabsorbents were considered to eliminate these pollutants. SAHs based on polysaccharides have also been studied for the removal of heavy metals [18]. Toxic dyes and metal ions are soluble in water and, therefore, easily contaminate this resource [9,78-80]. The heavy metal ions often cited are divalent cations such as $\mathrm{Cu}^{2+}, \mathrm{Cd}^{2+}$, $\mathrm{Pb}^{2+}$, and $\mathrm{Fe}^{3+}$ while among synthetic dyes we find methylene blue, crystal violet, and malachite green [62]. Superabsorbents use their hydrophilic groups (such as $-\mathrm{COOH},-\mathrm{OH}$ or $-\mathrm{NH}_{2}$ ) to interact and attach to water pollutants. They then act as separators allowing the purification of the water [9]. Among polysaccharides, chitosan-based superabsorbents have been widely studied. For example, a crosslinked chitosan-graft-poly(maleic acid) was prepared to absorb $\mathrm{Hg}^{2+}$ ions [81] while another superabsorbent with chitosan and bentonite clay was prepared to remove malachite green and methyl violet dyes [82]. Similarly, poly(acrylic acid) grafted to chitosan was used for the removal of $\mathrm{Cu}^{2+}$ and $\mathrm{Cd}^{2+}$ ions [11]. Other polysaccharides such as cellulose, Arabic gum, starch, and alginate with grafted synthetic compounds have also been reported for the removal of metals and dyes from water $[10,11,18]$.

\subsection{Building Applications}

SAPs have also been studied in recent years for applications in mortar and concrete. These applications mainly concern the self-sealing and self-healing of concrete cracks [11]. Indeed, these are promising for repairing cracks without external human intervention but also for reducing building maintenance costs [15]. In concrete, water has an important role since it is responsible for initial hydration of cement and for its deterioration by humidity in the hard state. Water can cause early-age cracking of concrete by autogenous shrinkage. Consequently, SAPs were used to mitigate early cracking of concrete by autogenous shrinkage. They have been commercialized in particular for the internal hardening of high-performance concretes. Indeed, the structure of these concretes prevents the migration of water from the external surface to the interior of the concrete during early hardening. Therefore, the cement needs additional water to hydrate all the concrete and cause it to harden. SAPs can provide this necessary additional humidity by releasing absorbed water inside concrete. The water supplied will be able to compensate the loss of resistance due to the evaporation of water at the surface and prevent autogenous stresses that may lead to cracking [10,49].

In order to harden cement-based materials and mitigate concrete cracks, polysaccharides such as carrageenan, chitosan, and xanthan gum have been investigated as biosourced SAPs [49]. For example, SAHs with alginate, agarose, and chitosan methacrylated and crosslinked with amine-based monomers were prepared. These materials had $\mathrm{pH}$-sensitive self-healing properties and can, therefore, be used to seal cracks in buildings. When the $\mathrm{pH}$ is high (fresh mortar), these hydrogels have a low swelling capacity and create macropores in hardened concrete. When water enters the formed crevices, it is absorbed by SAHs, which swell and seal the crack. Another example of hydrogel with modified alginate has been reported to create concrete with self-healing properties [11].

\subsection{Other Applications}

Polysaccharide-based superabsorbents can also be used for other applications not described before, but their uses are not always well described in the literature. Applications for electrical purposes and for food packaging have been cited. Among these, superabsorbents can be used as tapes and coatings for electric cables to prevent water from entering if the outer coating is damaged [11]. SAP with starch-grafted sodium polyacrylates were bound to cables of fiber optic by an alcohol-soluble nylon binder. SAP power was inserted between or on the ribbon stack of fiber optic to block water. Moreover, SAP powders are used to preserve aqueous liquids in food packaging too. For example, crosslinked carboxymethylcellulose was applied as superabsorbent. The package that was created featured a strip with the superabsorbent powder and supportive materials to retain fluids [10]. 


\section{Conclusions and Future Prospectives}

Superabsorbents have received increasing interest in recent years for their attractive ability to absorb and retain large amounts of fluids. The market prospective for superabsorbents is very promising because of the growth of end-user industries, which in turn rests on the growth of a world population needing more and more personal hygiene products. The growing medical requirements of the ailing population are also being anticipated as a major reason for the growth of the superabsorbent polymer market. The global superabsorbent polymer market is anticipated to become a USD 8.6 billion market by 2021 (https://www.researchandmarkets.com). It was seen in this review that superabsorbents could be distinguished according to several factors but that the most suitable and used classification was based on the origin of the crosslinked polymers. Currently, the most commercially available superabsorbents are composed of synthetic polymers. Their absorption capacity is often very high, which makes them good materials for various applications, but the new environmental concerns about toxic waste are leading manufacturers to turn to more natural materials. To meet these needs, polysaccharides were then more widely studied to synthesize superabsorbents. They have absorption capacities that are often inferior to their synthetic counterparts, but still advantageous. Moreover, their biodegradability allows additional uses in agriculture and their biocompatibility for applications in the biomedical field. It is also possible to graft synthetic monomers or polymers to these biosourced polymers in order to combine their properties for specific applications. Characterization techniques have often been used to assess the properties of these materials and examine their structures. Many scientists have studied polysaccharide-based superabsorbents, resulting in an increase in the number of publications in recent years. The industrialists did the same with the request for patent publication on this subject. However, despite potential applications in the fields of hygiene and biomedical, agriculture, water treatment, and building, relatively few products with polysaccharides have been marketed to date. Based on the information presented in this review, the demand for superabsorbent materials will likely continue to grow. The low cost and the abundance of natural polymers, which additionally present interesting properties for promising applications, could lead to a more massive production of polysaccharide-based superabsorbents in the future. Nevertheless, to stimulate the market size of these materials, it is necessary for the legislation to lean towards a restriction or a ban on toxic synthetic ones. This would promote the development of production processes for natural superabsorbents with the emergence of new regulations. Consumers should also adhere to new products by changing their habits so that increased consumption of polysaccharide-based superabsorbents can offset their large-scale production costs.

Funding: This research received no external funding

Conflicts of Interest: The authors declare no conflict of interest, financial or otherwise.

\section{References}

1. Snoeck, D. Self-Healing and Microstructure of Cementitious Materials with Microfibres and Superabsorbent Polymers; Ghent University: Ghent, Belgium, 2015.

2. Wichterle, O.; Lím, D. Hydrophilic Gels for Biological Use. Nat. Cell Biol. 1960, 185, 117-118. [CrossRef]

3. Gibas, I.; Janik, H. Review: Synthetic polymer hydrogels for biomedical applications. Chem. Chem. Technol. 2010, 4, 297-304.

4. Lim, F.; Sun, A.M. Microencapsulated islets as bioartificial endocrine pancreas. Science 1980, $210,908-910$. [CrossRef] [PubMed]

5. Yannas, I.V.; Lee, E.; Orgill, D.P.; Skrabut, E.M.; Murphy, G.F. Synthesis and characterization of a model extracellular matrix that induces partial regeneration of adult mammalian skin. Proc. Natl. Acad. Sci. USA 1989, 86, 933-937. [CrossRef] [PubMed]

6. Guilherme, M.R.; Aouada, F.A.; Fajardo, A.R.; Martins, A.F.; Paulino, A.T.; Davi, M.F.; Rubira, A.F.; Muniz, E.C. Superabsorbent hydrogels based on polysaccharides for application in agriculture as soil conditioner and nutrient carrier: A review. Eur. Polym. J. 2015, 72, 365-385. [CrossRef] 
7. Sinha, S. 14-Biodegradable superabsorbents: Methods of preparation and application-A review. In Fundamental Biomaterials: Polymers; Thomas, S., Balakrishnan, P., Sreekala, M.S., Eds.; Woodhead Publishing: Cambridge, UK, 2018; pp. 307-322. [CrossRef]

8. Vasile, C.; Pamfil, D.; Stoleru, E.; Baican, M. New Developments in Medical Applications of Hybrid Hydrogels Containing Natural Polymers. Molecules 2020, 25, 1539. [CrossRef] [PubMed]

9. Chen, Y. Hydrogels Based on Natural Polymers; Elsevier: Amsterdam, The Netherlands, 2020; p. 552. [CrossRef]

10. Mehr, M.J.Z.; Omidian, H.; Doroudiani, S.; Kabiri, K. Advances in non-hygienic applications of superabsorbent hydrogel materials. J. Mater. Sci. 2010, 45, 5711-5735. [CrossRef]

11. Pérez-Álvarez, L.; Ruiz-Rubio, L.; Lizundia, E.; Vilas-Vilela, J.L. Polysaccharide-Based Superabsorbents: Synthesis, Properties, and Applications. In Cellulose-Based Superabsorbent Hydrogels; Mondal, M.I.H., Ed.; Springer Nature: Cham, Switzerland, 2019; pp. 1393-1431. [CrossRef]

12. Díez-Pascual, A.M. Synthesis and Applications of Biopolymer Composites. Int. J. Mol. Sci. 2019, $20,2321$. [CrossRef]

13. Jiang, F.; Hsieh, Y.-L. Amphiphilic superabsorbent cellulose nanofibril aerogels. J. Mater. Chem. A 2014, 2, 6337-6342. [CrossRef]

14. Jeddi, M.K.; Laitinen, O.; Liimatainen, H. Magnetic superabsorbents based on nanocellulose aerobeads for selective removal of oils and organic solvents. Mater. Des. 2019, 183, 108115. [CrossRef]

15. Mignon, A.; De Belie, N.; Dubruel, P.; Van Vlierberghe, S. Superabsorbent polymers: A review on the characteristics and applications of synthetic, polysaccharide-based, semi-synthetic and 'smart' derivatives. Eur. Polym. J. 2019, 117, 165-178. [CrossRef]

16. Capezza, A.J.; Wu, Q.; Newson, W.R.; Olsson, R.T.; Espuche, E.; Johansson, E.; Hedenqvist, M.S. Superabsorbent and Fully Biobased Protein Foams with a Natural Cross-Linker and Cellulose Nanofibers. ACS Omega 2019, 4, 18257-18267. [CrossRef] [PubMed]

17. Horie, K.; Barón, M.; Fox, R.B.; He, J.; Hess, M.; Kahovec, J.; Kitayama, T.; Kubisa, P.; Maréchal, E.; Mörmann, W.; et al. Definitions of terms relating to reactions of polymers and to functional polymeric materials (IUPAC Recommendations 2003). Pure Appl. Chem. 2004, 76, 889-906. [CrossRef]

18. Bhatia, J.K.; Kaith, B.S.; Kalia, S. Polysaccharide Hydrogels: Synthesis, Characterization, and Applications. In Polysaccharide Based Graft Copolymers; Kalia, S., Sabaa, M.W., Eds.; Springer: Heidelberg, Germany, 2013; pp. 271-290. [CrossRef]

19. Mignon, A. Effect of pH-Responsive Superabsorbent Polymers on the Self-Sealing and Self-Healing of Cracks in Concrete; Ghent University: Ghent, Belgium, 2016.

20. Yabuki, A.; Tanabe, S.; Fathona, I.W. Self-healing polymer coating with the microfibers of superabsorbent polymers provides corrosion inhibition in carbon steel. Surf. Coat. Technol. 2018, 341, 71-77. [CrossRef]

21. Qiao, D.; Liu, H.; Yu, L.; Bao, X.; Simon, G.P.; Petinakis, E.; Chen, L. Preparation and characterization of slow-release fertilizer encapsulated by starch-based superabsorbent polymer. Carbohydr. Polym. 2016, 147, 146-154. [CrossRef]

22. Aiouaz, N. Synthèse Et Propriétés De Superabsorbants Composites A Base De Polysaccharides; University of Science and Technology Houari Boumediene: Bab Ezzouar, Algeria, 2013.

23. Boumalha, H. Elaboration De Materiaux Composites Polymeres Superabsorbants/Additifs Et Etude Leurs Performances, Pour Une Application Dans Les Produits D'hygiene; University of Science and Technology Houari Boumediene: Bab Ezzouar, Algeria, 2019.

24. Pourjavadi, A.; Zeidabadi, F.; Barzegar, S. Alginate-based biodegradable superabsorbents as candidates for diclofenac sodium delivery systems. J. Appl. Polym. Sci. 2010, 118, 2015-2023. [CrossRef]

25. Ahmed, E.M. Hydrogel: Preparation, characterization, and applications: A review. J. Adv. Res. 2015, 6, 105-121. [CrossRef]

26. Olad, A.; Doustdar, F.; Gharekhani, H. Starch-based semi-IPN hydrogel nanocomposite integrated with clinoptilolite: Preparation and swelling kinetic study. Carbohydr. Polym. 2018, 200, 516-528. [CrossRef]

27. Rinaudo, M. Main properties and current applications of some polysaccharides as biomaterials. Polym. Int. 2008, 57, 397-430. [CrossRef]

28. Yadav, H.; Karthikeyan, C. 1-Natural polysaccharides: Structural features and properties. In Polysaccharide Carriers for Drug Delivery; Maiti, S., Jana, S., Eds.; Woodhead Publishing: Sawston, UK; Cambridge, UK, 2019; pp. 1-17. [CrossRef] 
29. Roberts, J.J.; Martens, P.J. 9-Engineering biosynthetic cell encapsulation systems. In Biosynthetic Polymers for Medical Applications; Poole-Warren, L., Martens, P., Green, R., Eds.; Woodhead Publishing: Cambridge, UK, 2016; pp. 205-239. [CrossRef]

30. Sayah, M.Y.; Chabir, R.; Benyahia, H.; Kandri, Y.R.; Chahdi, F.O.; Touzani, H.; Errachidi, F. Yield, Esterification Degree and Molecular Weight Evaluation of Pectins Isolated from Orange and Grapefruit Peels under Different Conditions. PLoS ONE 2016, 11, e0161751. [CrossRef]

31. Hadrich, A. Nouveaux Hydrogels A Base De Polysaccharide Obtenus Par Voie Biomimetique Ou Par Photoreticulation; University of Rouen Normandy: Rouen Normandy, France, 2019.

32. Warson, H. Modern Superabsorbent Polymer Technology. Polym. Int. 2000, 49, 1548. [CrossRef]

33. Chang, C.; Duan, B.; Cai, J.; Zhang, L. Superabsorbent hydrogels based on cellulose for smart swelling and controllable delivery. Eur. Polym. J. 2010, 46, 92-100. [CrossRef]

34. Li, Q.; Ma, Z.; Yue, Q.; Gao, B.; Li, W.; Xu, X. Synthesis, characterization and swelling behavior of superabsorbent wheat straw graft copolymers. Bioresour. Technol. 2012, 118, 204-209. [CrossRef] [PubMed]

35. Sudarsan, S.; Franklin, D.; Sakthivel, M.; Guhanathan, S. Non toxic, antibacterial, biodegradable hydrogels with pH-stimuli sensitivity: Investigation of swelling parameters. Carbohydr. Polym. 2016, 148, 206-215. [CrossRef]

36. Fang, S.; Wang, G.; Li, P.; Xing, R.; Liu, S.; Qin, Y.; Yu, H.; Chen, X.; Li, K. Synthesis of chitosan derivative graft acrylic acid superabsorbent polymers and its application as water retaining agent. Int. J. Biol. Macromol. 2018, 115, 754-761. [CrossRef]

37. Das, N. Preparation methods and properties of hydrogel: A review. Int. J. Pharm. Pharm. Sci. 2013, 5, $12-117$.

38. Pourjavadi, A.; Barzegar, S. Synthesis and Evaluation of $\mathrm{pH}$ and Thermosensitive Pectin-Based Superabsorbent Hydrogel for Oral Drug Delivery Systems. Starch Stärke 2009, 61, 161-172. [CrossRef]

39. Yoshimura, T.; Sengoku, K.; Fujioka, R. Pectin-based surperabsorbent hydrogels crosslinked by some chemicals: Synthesis and characterization. Polym. Bull. 2005, 55, 123-129. [CrossRef]

40. Pourjavadi, A.; Harzandi, A.; Hosseinzadeh, H. Modified carrageenan 3. Synthesis of a novel polysaccharide-based superabsorbent hydrogel via graft copolymerization of acrylic acid onto kappa-carrageenan in air. Eur. Polym. J. 2004, 40, 1363-1370. [CrossRef]

41. Shi, W.; Dumont, M.-J.; Ly, E.B. Synthesis and properties of canola protein-based superabsorbent hydrogels. Eur. Polym. J. 2014, 54, 172-180. [CrossRef]

42. Spagnol, C.; Rodrigues, F.H.; Pereira, A.G.; Fajardo, A.R.; Rubira, A.F.; Muniz, E.C. Superabsorbent hydrogel composite made of cellulose nanofibrils and chitosan-graft-poly(acrylic acid). Carbohydr. Polym. 2012, 87, 2038-2045. [CrossRef]

43. Alam, N.; Christopher, L.P. Natural Cellulose-Chitosan Cross-Linked Superabsorbent Hydrogels with Superior Swelling Properties. ACS Sustain. Chem. Eng. 2018, 6, 8736-8742. [CrossRef]

44. Zhang, J.; Xiao, H.; Li, N.; Ping, Q.; Zhang, Y. Synthesis and characterization of super-absorbent hydrogels based on hemicellulose. J. Appl. Polym. Sci. 2015, 132, 132. [CrossRef]

45. Kabiri, K.; Omidian, H.; Hashemi, S.; Zohuriaan-Mehr, M. Synthesis of fast-swelling superabsorbent hydrogels: Effect of crosslinker type and concentration on porosity and absorption rate. Eur. Polym. J. 2003, 39, 1341-1348. [CrossRef]

46. Zhu, W.; Zhang, Y.; Wang, P.; Yang, Z.; Yasin, A.; Zhang, L. Preparation and Applications of Salt-Resistant Superabsorbent Poly (Acrylic Acid-Acrylamide/Fly Ash) Composite. Materials 2019, 12, 596. [CrossRef]

47. Rodrigues, F.H.A.; Fajardo, A.R.; Pereira, A.G.B.; Ricardo, N.M.P.S.; Feitosa, J.P.A.; Muniz, E.C. Chitosan-graft-poly(acrylic acid)/rice husk ash based superabsorbent hydrogel composite: Preparation and characterization. J. Polym. Res. 2012, 19, 1-10. [CrossRef]

48. Liu, T.; Wang, Y.; Li, B.; Deng, H.; Huang, Z.; Qian, L.; Wang, X. Urea free synthesis of chitin-based acrylate superabsorbent polymers under homogeneous conditions: Effects of the degree of deacetylation and the molecular weight. Carbohydr. Polym. 2017, 174, 464-473. [CrossRef]

49. Aday, A.N.; Srubar, W.V. 2-Biobased polymers for mitigating early- and late-age cracking in concrete. In Bio-Based Materials and Biotechnologies for Eco-Efficient Construction; Pacheco-Torgal, F., Ivanov, V., Tsang, D.C.W., Eds.; Woodhead Publishing: Cambridge, UK, 2020; pp. 19-41. [CrossRef]

50. Jenkins, A.D.; Kratochvíl, P.; Stepto, R.F.T.; Suter, U.W. Glossary of basic terms in polymer science (IUPAC Recommendations 1996). Pure Appl. Chem. 1996, 68, 2287-2311. [CrossRef] 
51. Akhtar, M.F.; Hanif, M.; Ranjha, N.M. Methods of synthesis of hydrogels A review. Saudi Pharm. J. 2016, 24, 554-559. [CrossRef]

52. Jiang, F.; Hsieh, Y.-L. Super water absorbing and shape memory nanocellulose aerogels from TEMPO-oxidized cellulose nanofibrils via cyclic freezing-thawing. J. Mater. Chem. A 2014, 2, 350-359. [CrossRef]

53. Zohuriaan, M.J.-M.; Kabiri, K. Superabsorbent Polymer Materials: A Review. Iran. Polym. J. Engl. Ed. 2008, $17,451-447$.

54. Mechtcherine, V.; Snoeck, D.; Schröfl, C.; De Belie, N.; Klemm, A.J.; Ichimiya, K.; Moon, J.; Wyrzykowski, M.; Lura, P.; Toropovs, N.; et al. Testing superabsorbent polymer (SAP) sorption properties prior to implementation in concrete: Results of a RILEM Round-Robin Test. Mater. Struct. 2018, 51, 28. [CrossRef]

55. Shahi, S.; Motasadizadeh, H.R.; Mehr, M.J.Z. Surface Modification of Superabsorbing Hydrogels via a Feasible Esterification Reaction: Towards Tunable Superabsorbent for Hygienic Applications. Int. J. Polym. Mater. 2017, 66, 544-557. [CrossRef]

56. Sharma, P.R.; Chattopadhyay, A.; Zhan, C.; Sharma, S.K.; Geng, L.; Hsiao, B.S. Lead removal from water using carboxycellulose nanofibers prepared by nitro-oxidation method. Cellulose 2018, 25, 1961-1973. [CrossRef]

57. Liu, W.; Qin, Y.; Liu, S.; Xing, R.; Yu, H.; Chen, X.; Li, K.; Li, P. C-coordinated O-carboxymethyl chitosan metal complexes: Synthesis, characterization and antifungal efficacy. Int. J. Biol. Macromol. 2018, 106, 68-77. [CrossRef] [PubMed]

58. Qin, Y. 6-Superabsorbent polymers and their medical applications. In Medical Textile Materials; Qin, Y., Ed.; Woodhead Publishing: Cambridge, UK, 2016; pp. 71-88. [CrossRef]

59. Kosemund, K.; Schlatter, H.; Ochsenhirt, J.L.; Krause, E.L.; Marsman, D.S.; Erasala, G.N. Safety evaluation of superabsorbent baby diapers. Regul. Toxicol. Pharmacol. 2009, 53, 81-89. [CrossRef]

60. Srinivas, S.M.; Dhar, S. Advances in diaper technology. Indian J. Paediatr. Dermatol. 2016, 17, 83. [CrossRef]

61. Sannino, A.; Demitri, C.; Madaghiele, M. Biodegradable Cellulose-based Hydrogels: Design and Applications. Materials 2009, 2, 353-373. [CrossRef]

62. Cheng, B.; Pei, B.; Wang, Z.; Hu, Q. Advances in chitosan-based superabsorbent hydrogels. RSC Adv. 2017, 7, 42036-42046. [CrossRef]

63. Huppe, S.; Maheux, M.-E.; Chevigny, S.; Quirion, F. Glass-Like Polysaccharide Useful as Absorbent for Liquids. WO2000CA00555, 11 May 2000.

64. De France, K.J.; Hoare, T.; Cranston, E.D. Review of Hydrogels and Aerogels Containing Nanocellulose. Chem. Mater. 2017, 29, 4609-4631. [CrossRef]

65. Hoggarth, A.; Bugedo, A.; Hardy, C. Wound Dressing. WO2016/174399A1, 4 August 2016.

66. Hardy, G.; Hoggarth, A.; Warde, D. Wound Dressing. CA2943012A1, 24 September 2015.

67. Hua, S.; Wang, A. Synthesis, characterization and swelling behaviors of sodium alginate-g-poly(acrylic acid)/sodium humate superabsorbent. Carbohydr. Polym. 2009, 75, 79-84. [CrossRef]

68. Nascimento, D.M.; Nunes, Y.L.; Figueirêdo, M.C.B.; De Azeredo, H.M.C.; Aouada, F.A.; Feitosa, J.P.A.; Rosa, M.D.F.; Dufresne, A. Nanocellulose nanocomposite hydrogels: Technological and environmental issues. Green Chem. 2018, 20, 2428-2448. [CrossRef]

69. Li, S.; Chen, G. Agricultural waste-derived superabsorbent hydrogels: Preparation, performance, and socioeconomic impacts. J. Clean. Prod. 2020, 251, 119669. [CrossRef]

70. Yang, X.; Cranston, E.D. Chemically Cross-Linked Cellulose Nanocrystal Aerogels with Shape Recovery and Superabsorbent Properties. Chem. Mater. 2014, 26, 6016-6025. [CrossRef]

71. Sharma, P.R.; Sharma, S.K.; Borges, W.; Chen, H.; Hsiao, B.S. Remediation of UO2 2+ from Water by Nitro-Oxidized Carboxycellulose Nanofibers: Performance and Mechanism. In Contaminants in Our Water: Identification and Remediation Methods; Ahuja, S., Loganathan, B.G., Eds.; American Chemical Society: Washington, DC, USA, 2020; Volume 1352, pp. 269-283. [CrossRef]

72. Bortolin, A.; Serafim, A.R.; Aouada, F.A.; Mattoso, L.H.C.; Ribeiro, C. Macro- and Micronutrient Simultaneous Slow Release from Highly Swellable Nanocomposite Hydrogels. J. Agric. Food Chem. 2016, 64, 3133-3140. [CrossRef] [PubMed]

73. Zhou, C.; Wu, Q.; Lei, T.; Negulescu, I.I. Adsorption kinetic and equilibrium studies for methylene blue dye by partially hydrolyzed polyacrylamide/cellulose nanocrystal nanocomposite hydrogels. Chem. Eng. J. 2014, 251, 17-24. [CrossRef]

74. Keller, H.; Wissemeier, A.; Weigelt, W.; Sanz-Gomez, J.; Yamamoto, M. Polysaccharide Hydrogels. WO2015097033, 2 July 2015. 
75. Savich, M.H.; Olson, G.S.; Clark, E.W. Superabsorbent Polymer Suspension for Use in Agriculture. CA2693796A1, 5 January 2016.

76. Borriello, A.; Baldino, L.; Cardea, S.; Reverchon, E.; Nicolais, L. Process for Preparing A Superabsorbent Aerogel. WO2019167013, 6 September 2019.

77. Sharma, P.R.; Sharma, S.K.; Lindström, T.; Hsiao, B.S. Nanocellulose-Enabled Membranes for Water Purification: Perspectives. Adv. Sustain. Syst. 2020, 4, 1900114. [CrossRef]

78. Peng, N.; Hu, D.; Zeng, J.; Li, Y.; Liang, L.; Chang, C. Superabsorbent Cellulose-Clay Nanocomposite Hydrogels for Highly Efficient Removal of Dye in Water. ACS Sustain. Chem. Eng. 2016, 4, 7217-7224. [CrossRef]

79. Chen, H.; Sharma, S.K.; Sharma, P.R.; Yeh, H.; Johnson, K.; Hsiao, B.S. Arsenic (III) Removal by Nanostructured Dialdehyde Cellulose-Cysteine Microscale and Nanoscale Fibers. ACS Omega 2019, 4, 22008-22020. [CrossRef]

80. Sharma, P.R.; Sharma, S.K.; Antoine, R.; Hsiao, B.S. Efficient Removal of Arsenic Using Zinc Oxide Nanocrystal-Decorated Regenerated Microfibrillated Cellulose Scaffolds. ACS Sustain. Chem. Eng. 2019, 7,6140-6151. [CrossRef]

81. Ge, H.; Hua, T. Synthesis and characterization of poly (maleic acid)-grafted crosslinked chitosan nanomaterial with high uptake and selectivity for Hg (II) sorption. Carbohydr. Polym. 2016, 153, 246-252. [CrossRef] [PubMed]

82. Bhattacharyya, R.; Ray, S.K. Micro- and nano-sized bentonite filled composite superabsorbents of chitosan and acrylic copolymer for removal of synthetic dyes from water. Appl. Clay Sci. 2014, 101, 510-520. [CrossRef]

Publisher's Note: MDPI stays neutral with regard to jurisdictional claims in published maps and institutional affiliations. 